\title{
Investigation of Particulate Matter Size, Concentration and Mass Emissions from Small Handheld 2-Stroke Spark Ignition Engines
}

\author{
Yashwanth Chowdary Maddineni
}

Follow this and additional works at: https://researchrepository.wvu.edu/etd

\author{
Recommended Citation \\ Maddineni, Yashwanth Chowdary, "Investigation of Particulate Matter Size, Concentration and Mass \\ Emissions from Small Handheld 2-Stroke Spark Ignition Engines" (2016). Graduate Theses, Dissertations, \\ and Problem Reports. 6135. \\ https://researchrepository.wvu.edu/etd/6135
}

This Thesis is protected by copyright and/or related rights. It has been brought to you by the The Research Repository @ WVU with permission from the rights-holder(s). You are free to use this Thesis in any way that is permitted by the copyright and related rights legislation that applies to your use. For other uses you must obtain permission from the rights-holder(s) directly, unless additional rights are indicated by a Creative Commons license in the record and/ or on the work itself. This Thesis has been accepted for inclusion in WVU Graduate Theses, Dissertations, and Problem Reports collection by an authorized administrator of The Research Repository @ WVU. For more information, please contact researchrepository@mail.wvu.edu. 
Investigation of Particulate Matter Size, Concentration and Mass Emissions from Small Handheld 2-Stroke Spark Ignition Engines

Yashwanth Chowdary Maddineni

Thesis submitted

to the College of Engineering and Mineral Resources

at West Virginia University

in partial fulfillment of the requirements for the degree of

Master of Science

in

Mechanical Engineering

Arvind Thiruvengadam, Ph.D., Chair

V'yacheslav Akkerman, Ph.D.

Cosmin Dumitrescu, Ph.D.

Department of Mechanical and Aerospace Engineering

Morgantown, West Virginia

2016

Keywords: Handheld Engines, 2-Stroke SI Engines, SMPS, Particle Size Distribution, Heat-treatment

Copyright 2016 Yashwanth Chowdary Maddineni 


\section{ABSTRACT \\ Investigation of Particulate Matter Size, Concentration and Mass Emissions from Small Handheld 2-Stroke Spark Ignition Engines}

Yashwanth Chowdary Maddineni

Quality of air, change in the climate and exposure of humans to pollutants have become major concerns globally over the past decade. Particulate matter has been linked to many adverse health effects. Internal combustion engines are major source of PM emissions. Knowing the adverse health effects of particulate matter, the regulatory agencies are in the process of introducing strict regulations to limit the quantity of PM emitted by off-road small handheld gasoline engines. Two-stroke small engines typically emit more smoke as they burn oil-gasoline mixture compared to four-stroke engines running on gasoline only. Current regulations in the United States for these engines regulate only $\mathrm{HC}+\mathrm{NOx}$ and $\mathrm{CO}$ emissions. In spite of their contribution to atmospheric pollution and negative health effects, the PM emissions from handheld, two-stroke engines are yet to be regulated. This led to this study of particulate matter emissions from these engines.

The main objective of this study was to measure particulate matter size, concentration and mass distributions from 2-stroke handheld $25 \mathrm{cc}$ weed whacker engine and to evaluate the effect of heat treatment on these emissions in removal of volatile fractions. The exhaust sample was heat treated to different temperatures $\left(200{ }^{\circ} \mathrm{C}, 150{ }^{\circ} \mathrm{C}\right.$, and $\left.100{ }^{\circ} \mathrm{C}\right)$ before measuring the distributions to better understand what fraction of particulate matter is solid or volatile. Tests were performed in Center for Alternate Fuels, Engines and Emissions Laboratory (CAFEE) at West Virginia University. A Scanning Mobility Particle Sizer (SMPS) Model was used for measuring the particle size distribution and concentrations. The engine was operated at two steady-state modes (wide open throttle) WOT and Idle mode. The WOT mode resulted in a count median diameter (CMD) of $14.1 \mathrm{~nm}$ when heat treated the sample to $200{ }^{\circ} \mathrm{C}$ compared to $32.1 \mathrm{~nm}$ for sample in CVS whereas the idle mode resulted in CMD of 5.94nm and $31.1 \mathrm{~nm}$ respectively. This indicated the existence of volatile particles. These Nano-particles are proved to be harmful to health. Results obtained from the data for the sample in CVS and compared to the data for the heat treated samples, show that the influence of volatile fraction on PM size distribution is reduced with increase in sample conditioning temperatures. The density function used for mass distribution calculations by SMPS does not take diameter of the particle into consideration and so these calculations were compared with the mass distribution calculated by using IPSD method or effective particle density method since previous studies indicated that at ultra-low emission levels this method proved to give more precise results. This comparison resulted in a good correlation in the particle mass distribution given by SMPS. 


\section{ACKOWLEDGEMENTS}

This is a point in my career where I have to thank my family for what I am today, for their unconditional love, support and freedom they gave me to choose what I wanted to be.

I would like to express my deepest gratitude to my advisor Dr. Arvind Thiruvengadam for supporting me all the way through my research and helping me start my career. Dr. Arvind, your guidance has provided me an invaluable experience that will help through the course of my career. Thanks for being patient with me all through this period.

I thank my committee members Dr. V'yacheslav Akkerman and Dr. Cosmin Dumitrescu for evaluating my thesis and I appreciate your time and effort to help me make it a good one.

A special thanks to Prathyusha Sridhara and Vishnu Padmanaban for supporting and helping me through my thesis. Finally, I would like to thank my roommates and all my friends at West Virginia University for making my stay in Morgantown, a very memorable one. 


\section{TABLE OF CONTENTS}

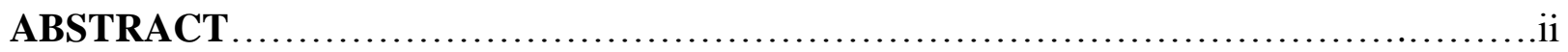

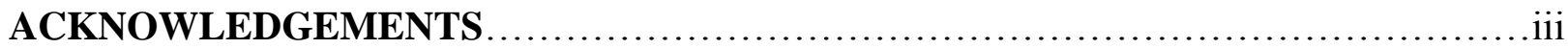

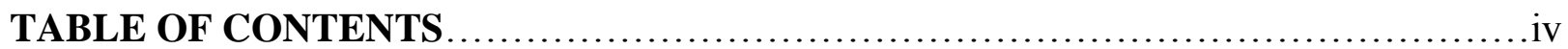

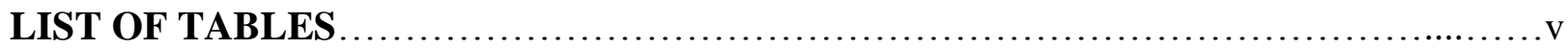

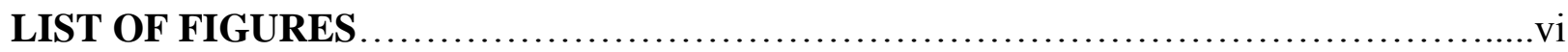

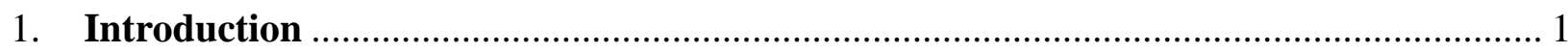

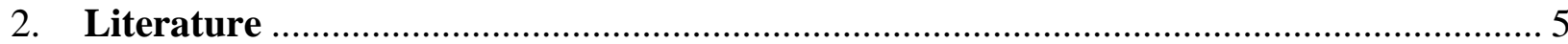

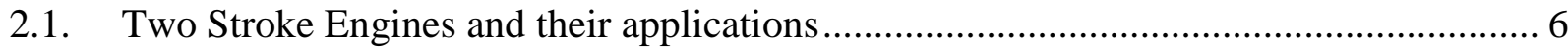

2.2. Overview of Emission Regulations for Small non-road SI Engines ................................ 7

2.3. Previous studies on Emissions from Handheld Spark Ignition Engines .......................... 8

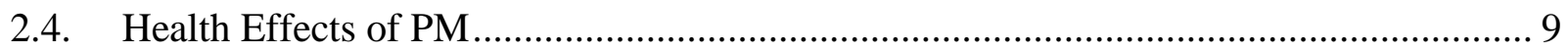

2.5. Particle Formation and Measurement of Particle Number ........................................... 13

2.6. PM Measurement Principle with Separation of Solid and Volatile Fraction .................. 15

3. Experimental Setup and Test Procedures ……........................................................ 18

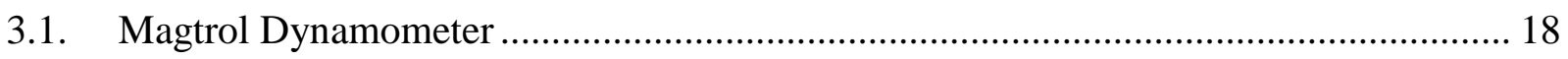

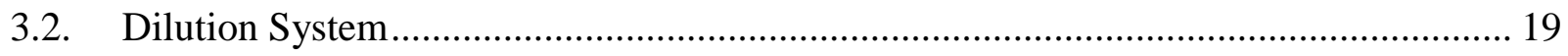

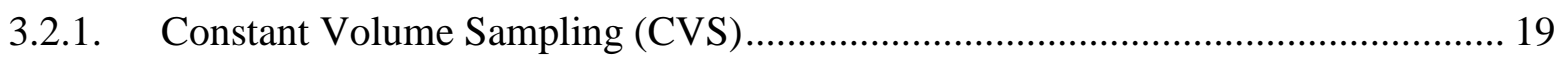

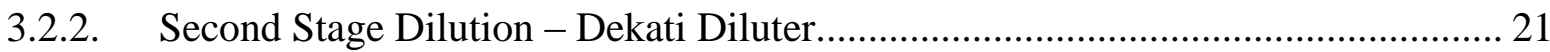

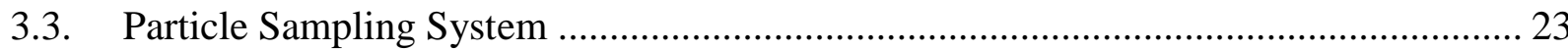

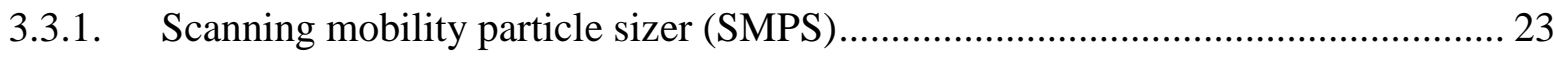

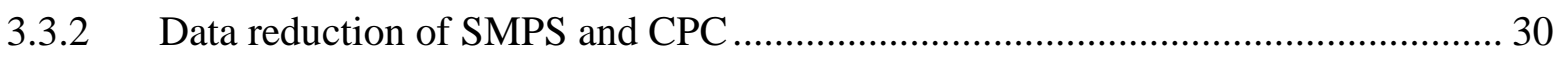

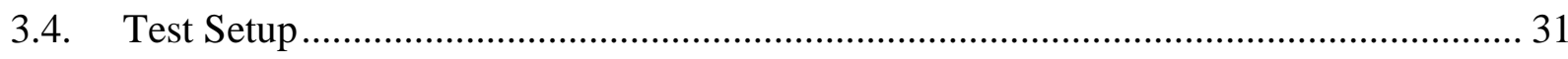

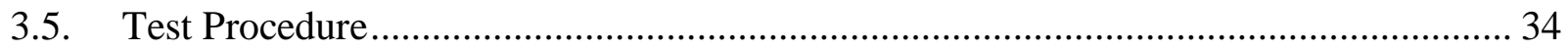

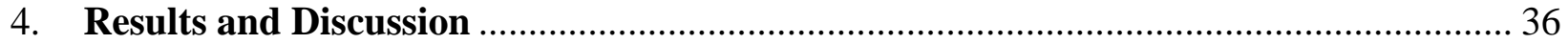

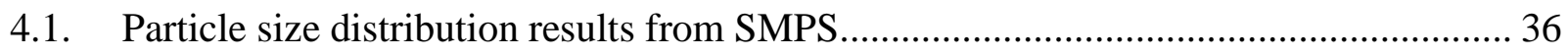

4.2. Integrated Particle Size Distribution (IPSD) method .................................................... 45

4.3. Mass comparison between SMPS and IPSD method.................................................. 47

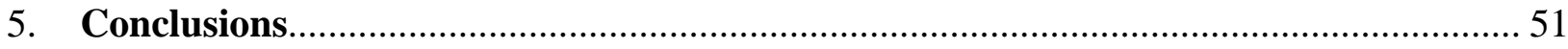

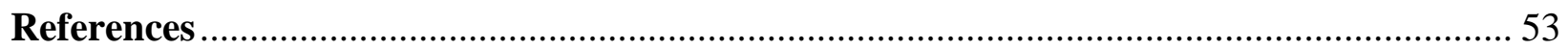




\section{List of Tables}

Table 1 : California Tier 3 Emission Standards for handheld SI engines................................. 8

Table 2 : EPA Phase 3 Emission Standards for handheld SI engines......................................... 8

Table 3 : Changes in physical properties of solid particles (Fritz, 2012) ................................. 14

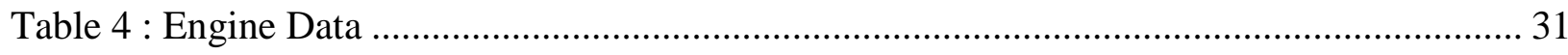

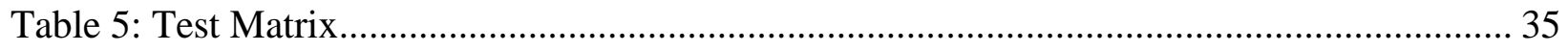

Table 6: CMD and GSD of particle size distributions at WOT mode ..................................... 44

Table 7: CMD and GSD of particle size distributions at idle mode ...................................... 45

Table 8: Mass Concentration of CMD particles from SMPS and IPSD distributions at WOT

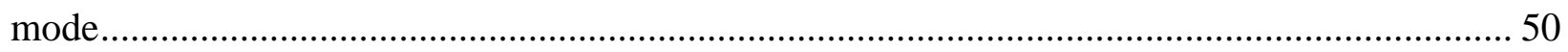

Table 9: Mass concentration of CMD particles from SMPS and IPSD distributions at idle mode 


\section{List of Figures}

Figure 1: Indicator Diagram for 2 stroke engines (Engineering , 2013)....

Figure 2 : The Major Features of the Human Respiratory System (National Air Pollution Control

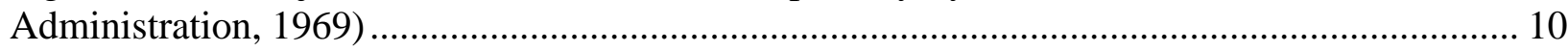

Figure 3 : Alveolar Region (National Air Pollution Control Administration, 1969).................. 11

Figure 4 : Particles Classification Based on the Diameter Size (Dp) .................................... 13

Figure 5: Separation of volatile particles using a thermal denuder in a study (Kittelson D. , 2015)

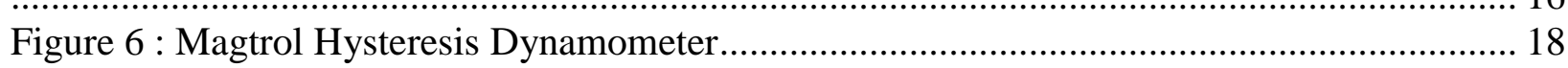

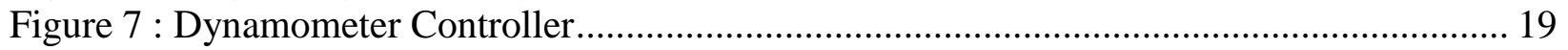

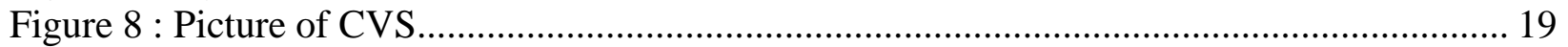

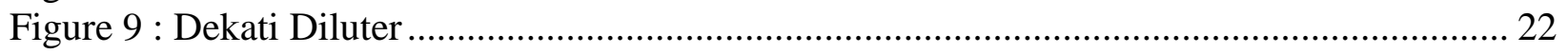

Figure 10 : Operation of Dekati Diluter (Dekati, 2016) ....................................................... 22

Figure 11 : Scanning Mobility Particle Sizer setup ........................................................... 23

Figure 12: Schematic Flow Diagram of Classifier with DMA (TSI, 1999) ............................. 24

Figure 13 : Schematic of the differential mobility analyzer (DMA) (TSI, 1999)..................... 25

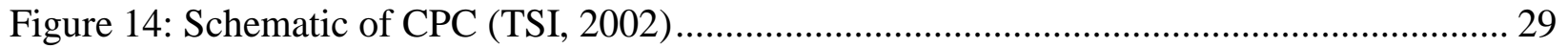

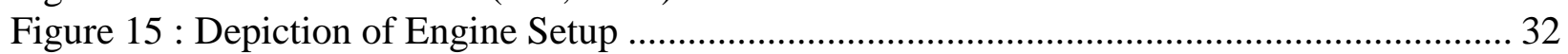

Figure 16: Depiction of Engine Setup on the Dyno........................................................... 32

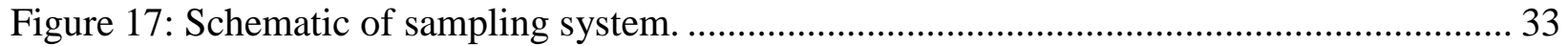

Figure 18: Particle size distribution of sample in CVS at WOT mode to check for engine stability

Figure 19: Particle size distribution of sample in CVS at Idle mode to check for engine stability

.

Figure 20: Particle Size Distribution by SMPS at WOT and Idle mode for sample in CVS....... 38

Figure 21: Particle Size Distribution at WOT mode and idle mode with Sample Conditioning

Temperature of $200{ }^{\circ} \mathrm{C}$ compared with Sample in CVS ............................................................ 39

Figure 22: Particle Size Distribution at WOT mode and idle mode with Sample Conditioning

Temperature of $150{ }^{\circ} \mathrm{C}$ compared with sample in CVS .................................................... 40

Figure 23: Particle Size Distribution at WOT mode and idle mode with Sample Conditioning

Temperature of $100{ }^{\circ} \mathrm{C}$ compared with sample in CVS ..................................................... 41

Figure 24: Particle size distributions with different sample conditioning temperatures at WOT

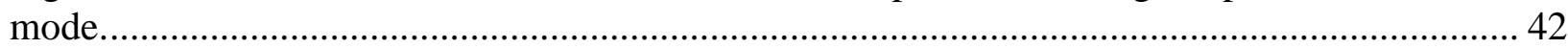

Figure 25: Particle size distributions with different sample conditioning temperatures at idle

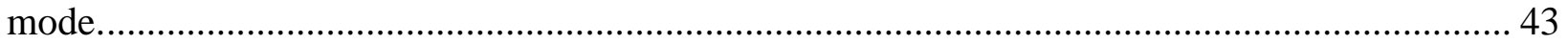

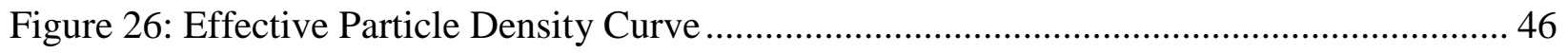

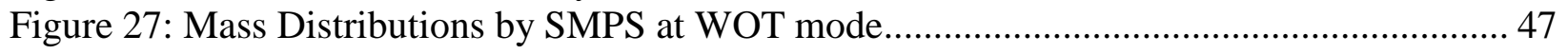

Figure 28: Mass Distributions calculated by IPSD method at WOT mode .............................. 48

Figure 29: Mass Distributions by SMPS at idle mode............................................................. 48

Figure 30: Mass Distributions calculated by IPSD method at idle mode ................................ 49 


\section{Introduction}

Quality of air, change in the climate and exposure of humans to pollutants have become major concerns globally over the past decade. Particulate matter has been linked to many adverse health effects. Internal combustion engines are major source of PM emissions. A multitude of studies were conducted in order to understand and limit the amount of particulate matter that is being exhausted from internal combustion engines. A large number of health studies have been conducted to determine the respiratory health-related effects attributed to total suspended particles and size distinct finer fractions (Monn, et al., 1995) (Rohr \& Wyzga, 2012)

Particulate matter (PM) is an air pollution term for a mixture of solid particles and liquid droplets found in the air (US EPA). It comes in a variety of sizes and can be composed of many types of materials and chemicals. This is a concern as particles that are small enough to be inhaled have negative health and environmental effects. EPA's (Environmental Protection Agency) particulate matter research has also affirmed the need for air quality standards to reduce PM in the air to protect human health. This ensued most countries to have regulations mainly in the transportation sector such as automotive and heavy truck markets which limit the quantity of particulate matter that can be emitted to the environment. As a result of these transportation sectors becoming cleaner, more of the emissions inventory burden has been falling on the adjacent market segments such as small non-road spark-ignition engine sector.

Gasoline engines emit very low levels of particulate matter compared to diesel engines. There are strict regulations in place for on road gasoline engines. So the concentration was shifted towards non road gasoline engines. However, all the United States, California and European regulatory agencies have already placed regulations for $\mathrm{HC}$, NOx, and $\mathrm{CO}$ for non- 
road engines by categorizing them into handheld and non-handheld engines. Keeping the effects of PM in mind now these regulatory agencies are in the process of introducing regulations to limit the quantity of particulate matter emitted by off-road small gasoline engines.

Approximately 500 million of small non-road two-stroke gasoline spark-ignition engines such as lawn and garden machines are produced annually, accounting for 5-10\% of total US emissions of carbon monoxide $(\mathrm{CO})$, carbon dioxide $\left(\mathrm{CO}_{2}\right)$, nitrogen oxides $\left(\mathrm{NO}_{\mathrm{x}}\right)$, hydrocarbons (HC), and fine particulate matter (PM2.5) (Code of Federal Regulation - CFR). This equipment contributed to 6\% PM2.5 (particulate matter with particle diameter less than $2.5 \mu \mathrm{m}$ ) to the United States emission inventory (Code of Federal Regulation - CFR). It was in 1990, when the California passed the first emissions standards for small SI engines used in lawn and garden equipment which were adopted by USEPA in 1995. The early regulations were met by improving fuel delivery systems or switching from two-stroke to four-stroke engines. In subsequent years the regulations were tightened which led manufactures to add catalysts.

Two-stroke small engines typically emit more smoke as they burn oil-gasoline mixture compared to four-stroke engines running on gasoline only. In spite of their contribution to atmospheric pollution and negative health effects, the particulate matter emissions from handheld, two-stroke gasoline engines are yet to be regulated in United States. The emissions from these engines that are being regulated are only $\mathrm{HC}+\mathrm{NO}_{\mathrm{x}}$ and $\mathrm{CO}$ emissions. This led to this study of particulate matter emissions from these engines. PM emissions consists of both solid and volatile compounds. As volatile particles are generally unburnt hydrocarbons for which regulations are in place, there is a need to focus mainly on solid fraction of particulate matter. Moreover, the close proximity of human exposure to the pollutants emitted from these engines, it is important to understand the characteristics of these PM emissions from hand held engines. The 
three properties that are necessary for a well-defined and comprehensive analysis of PM emissions include particle size, number and mass.

Many instruments are available for measuring particle size, number and mass. The instrument chosen for this study to investigate particulate matter from small handheld engines is a Scanning Mobility Particle Sizer (SMPS). This instrument has different operation and particle classification techniques which can give a clear information about the size, number and mass of the particles. The density function used by SMPS for calculating mass values doesn't take particle diameter in to consideration. So these mass calculations have to be validated. There are many methods to measure mass of the particles emitted one of which is Integrated Particle Size Distribution (IPSD) method or effective particle density method. This method is proved to provide precise results at low levels of mass measurements.

The Scanning Mobility Particle Sizer (SMPS) is basically a combination of two devices a Condensational Particle Counter (CPC) and an Electrostatic Classifier. The SMPS determines particle size distributions by sorting particles based on their electrical mobility. The exhaust sample mixed with dilution air is known as aerosol. The aerosol is charged using a neutralizer according Boltzmann distribution of charge (TSI, 1999). This poly-disperse charged aerosol then enters the Differential Mobility Analyzer (DMA). A narrow range of the electrical mobility's of positive ions pass through the Differential Mobility Analyzer and exits as a mono-disperse aerosol i.e. particles of one specific diameter. (Greenwood, Coxon, Biddulph, \& Bennett, 1996). This mono-disperse aerosol from the DMA of electrostatic classifier then enters the CPC where each particle of specific size is counted. 
The global objective of this thesis was to investigate the characteristics of particulate matter from the handheld two-stroke gasoline engines. The secondary objectives include

1) The change in the number concentration of PM particles of different sizes emitted from handheld two stroke engines thereby, to study the effect of volatile fraction on the OM emissions emitted from these small 2 stroke handheld spark ignition engines.

2) To find out the deviation in mass distribution calculated by SMPS with those calculated by Integrated Particle Size Distribution (IPSD) method or effective density method. 


\section{Literature}

In this twenty first century air pollution in general has been the real core interest of all the health and environmental related studies. Engines, whether stationary or mobile is one of the significant sources of air contamination. Engine emissions are generally classified into two particulate emissions and gaseous emissions. These emissions are exceedingly harmful as it affects the respiratory system. The regulatory bodies such as EPA have been imposing regulations in attempt to reduce these emissions from engines. So the engine manufacturers in order to comply with these set regulations, they are either developing their existing designs or are using different after treatment devices.

Gaseous emissions are measured according to the requirements of the CFR (Code of Federal Regulations) (USEPA, 40 Code of Federal Regulations Part 1065) imposed by Environmental Protection Agency. Particulate matter emissions are mass based emissions, so they are collected on a filter and weighed. Many studies (Rohr \& Wyzga, 2012) (Strak, et al., 2012) (International Agency Research on Cancer, 1989) (Health Effects Institute, 1995) indicate that those measurements must also include the size of the particles. New engines follow the regulations in terms of mass however in terms of number they emit very high concentrations especially in the size range below 100nm. These small particles don't add much towards mass, however contribute significantly towards number concentrations. Particles with size below $100 \mathrm{~nm}$ are called ultrafine particles and particles with size below 50nm are nanoparticles.

This chapter gives brief details of the current regulations in place for small handheld gasoline engines in the USA, the information from few studies on the formation, health issues caused by particulate matter, separation of volatile and solid fractions. 


\subsection{Two Stroke Engines and their applications}

A two-stroke engine is one which completes its cycle of operation in one revolution of the crankshaft or in two strokes of the piston. In these engines the functions of the intake and exhaust processes of the four-stroke engine are taken care by the incoming fresh charge which is compressed either in the crankcase or by means of a separate blower while the engine piston is near the bottom dead center. The engine piston when moving from bottom dead center to top dead center needs only to compress the fresh charge. The fresh charge entering the cylinder helps in exhausting the burnt gases out of the cylinder through the exhaust port. This process is called as scavenging. Since a two-stroke engine will have twice as many cycles per minute as a fourstroke engine operating at the same speed and with the same number of cylinders, theoretically it will develop twice the power when operating at the same mean effective pressure. The figure 1 below shows different strokes and valve operations in a typical two stroke engine.

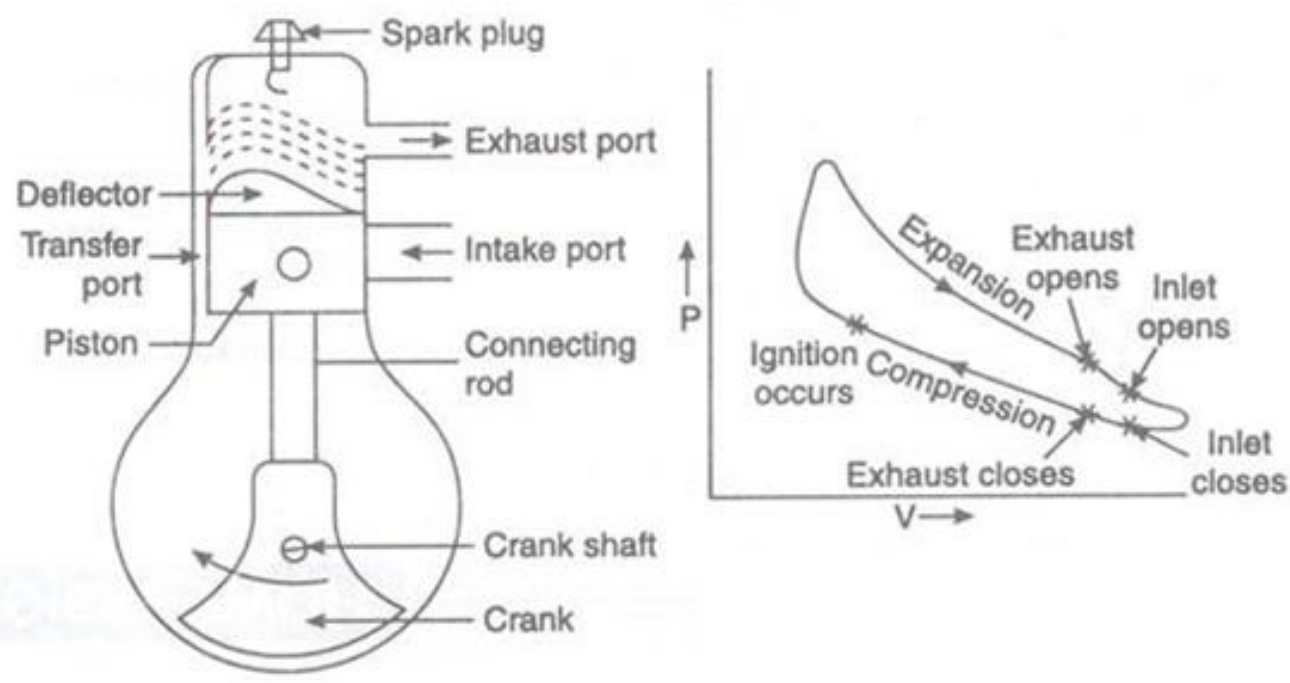

Figure 1: Indicator Diagram for 2 stroke engines (Engineering , 2013)

When compared to 4-stroke engines these engines are lighter in weight for same power output, the construction is simple and the work required to overcome the friction of the exhaust 
and suction strokes is saved. Majority of lawn equipment industry are using these 2 strokes engines considering all these advantages mainly while building handheld engines.

\subsection{Overview of Emission Regulations for Small non-road SI Engines}

In United States, EPA (Environmental Protection Agency) and CARB (California Air Resource Board) are the main regulatory bodies. All the engine manufactures should make sure that their engines comply with the required standards. Regulations on small SI (spark ignition) engines started way back in 1990 (Manufacturers of Emission Controls Association, 2009). CARB first passed its emission standards which came into effect in 1994. EPA also adopted similar standards which effected from 1997. Over the years, these regulatory bodies tightened the regulations. Though the regulation standards are similar, CARB and EPA have different names for these standards. CARB goes by Tier 1, Tier 2, Tier 3, whereas EPA follows the name Phase 1, Phase 2, Phase 3. Tier 3 and Phase 3 are current regulations followed by the gasoline engine manufacturers. (Manufacturers of Emission Controls Association, 2009)

The small SI engines can also be categorized as non-handheld and handheld engines which are further divided into different classes based on their engine displacement. The nonhandheld engines fall under two classes - Class I ( $<225 \mathrm{cc})$ and Class II (>225cc). The handheld engines have been classified into three classes - Class III (<20cc), Class IV (20-50cc) and Class V (>50cc) (Manufacturers of Emission Controls Association, 2009). The current regulations mainly focus on limits for $\mathrm{HC}_{+} \mathrm{NO}_{x}, \mathrm{CO}$ and $\mathrm{PM}$ emissions. Table 1 and table 2 below show the current emissions standards of Tier 3 and Phase 3 for handheld engines. 
Table 1 : California Tier 3 Emission Standards for handheld SI engines

\begin{tabular}{|c|c|c|c|c|}
\hline Model Year & Engine Class & $\begin{array}{c}\text { HC+NOx } \\
(\mathrm{g} / \mathrm{kW}-\mathrm{hr})\end{array}$ & $\begin{array}{c}\mathrm{CO} \\
(\mathrm{g} / \mathrm{kW}-\mathrm{hr})\end{array}$ & $\begin{array}{c}\text { Particulate(for 2 } \\
\text { stroke engine })\end{array}$ \\
\hline $\begin{array}{c}2005 \text { and } \\
\text { later }\end{array}$ & $<50 \mathrm{cc}$ & 50 & 536 & 2.0 \\
\cline { 2 - 5 } & $50-80 \mathrm{cc}$ & 72 & 536 & 2.0 \\
\hline
\end{tabular}

Table 2 : EPA Phase 3 Emission Standards for handheld SI engines

\begin{tabular}{|c|c|c|c|}
\hline \multirow{2}{*}{ Model Year } & Engine Class & $\begin{array}{c}\text { HC+NOx Limit } \\
(\mathrm{g} / \mathrm{kW}-\mathrm{hr})\end{array}$ & $\begin{array}{c}\mathrm{CO} \\
(\mathrm{g} / \mathrm{kW}-\mathrm{hr})\end{array}$ \\
\hline \multirow{2}{*}{$\begin{array}{c}2007 \text { and } \\
\text { later }\end{array}$} & Class III & 50 & 805 \\
\cline { 2 - 4 } & Class IV & 50 & 805 \\
\cline { 2 - 4 } & Class V & 72 & 603 \\
\hline
\end{tabular}

\subsection{Previous studies on Emissions from Handheld Spark Ignition Engines}

Handheld, gasoline-powered, spark-ignition engines are utilized by many people round the globe on a regular basis mainly for lawn and garden work. Despite the very important fact that these handheld engines release high organic and particulate matters, the study about these two-stroke engines hasn't been rigorous yet. These small two-stroke engines emit a variety of pollutants which include carbon monoxide $(\mathrm{CO})$, nitrogen oxides $\left(\mathrm{NO}_{\mathrm{x}}\right)$, hydrocarbons $(\mathrm{HC})$, and particulate matter. These engines contribute about $10.5 \%$ and $4.8 \%$ of $\mathrm{HC}$ and $\mathrm{CO}$ emissions respectively (EPA, 2005) and even emit more smoke than four stroke engines running on gasoline only, because they burn an oil-gas mixture which result in lack of emission controls and sometimes end up being irregularly maintained (Volckens, Braddock, Snow, \& Crews, 2007). The aerosol of the small mixture-lubricated 2-Stroke engine consists mostly of SOF originating from lube oil. (Czerwinski, Kurzwart, Mayer, \& Comte, 2014) 
Emission reductions in $\mathrm{CO}(78 \%)$ and $\mathrm{HC}(52 \%)$ were predominant between pre-control and phase- 2 engines which can be primarily due to improvements in engine design, reduced scavenging losses, and implementation of catalytic exhaust control. The use of a reformulated gasoline containing $10 \%$ ethanol resulted in a $15 \%$ decrease in $\mathrm{HC}$ and a $29 \%$ decrease in $\mathrm{CO}$ emissions, on an average. Increasing oil content of 2 -stroke engine fuels result in a substantial increase of PM2.5 emissions as well as smaller increase in $\mathrm{HC}$ and $\mathrm{CO}$ emissions (Volckens, Braddock, Snow, \& Crews, 2007).

In comparison to emissions from modern diesel engines, the PM emissions of small two stroke SI engines are very high and it is highly recommended to have these emissions regulated (Czerwinski, Wyser-Heusi, \& Mayer, 2001). Mass of the particulates and nanoparticle numbers both consisting unburned lube-oil reach very high values, which are strongly influenced by mixture of lube-oil content. (Czerwinski, Wyser-Heusi, \& Mayer, 2001).

\subsection{Health Effects of PM}

Particulate Matter, also known as PM, refers to the microscopic particles in the atmosphere which can be hazardous to health. The hazard is caused by the inhalation of these particles. It also depends on the particle's chemical composition and the area of deposition in the lungs (Strak, et al., 2012) (Hinds, 1999). The respiratory system is usually divided into three parts namely head airways region, tracheobronchial region and alveolar region. The nose, mouth and pharynx constitute the first part head airways region, the region from the trachea to the bronchioles is the second part tracheobronchial region and finally the terminal bronchioles, known as alveolar region where the gas exchange takes place. Human respiratory system is show in figure 2 . 
It is difficult to accurately predict the particle deposition in the lungs as there are a number of variables to be accounted for. These include the inhalation and exhalation rates, inhalation method (nose, mouth), airways geometry and relative humidity levels seen by the particle. These parameters clearly vary between individuals. The smaller the particles, the deeper will be the penetration into the respiratory system and the more dangerous they are to breathe. Many generalized models were developed to best describe the particle's path and the effect size (the aerodynamic equivalent diameter) of a particle has upon this course. Studies (Strak, et al., 2012) (Hinds, 1999) explains about different particle sizes and their health effects. The large coarse particles which are greater than $10 \mu \mathrm{m}$ in diameter do not have much impact on the health as they do not enter the respiratory tract beyond the entranceways. On the other hand, the smaller sized particles which are $2.5 \mu \mathrm{m}$ or less in diameter are of greatest concern to the health as they easily pass through the nose and mouth and be penetrated deep into the lungs. Lippmann, Gurman and Schlesinger (1983) found that the particles above $3.0 \mu \mathrm{m}$ have less pulmonary deposition due to diminished penetration.

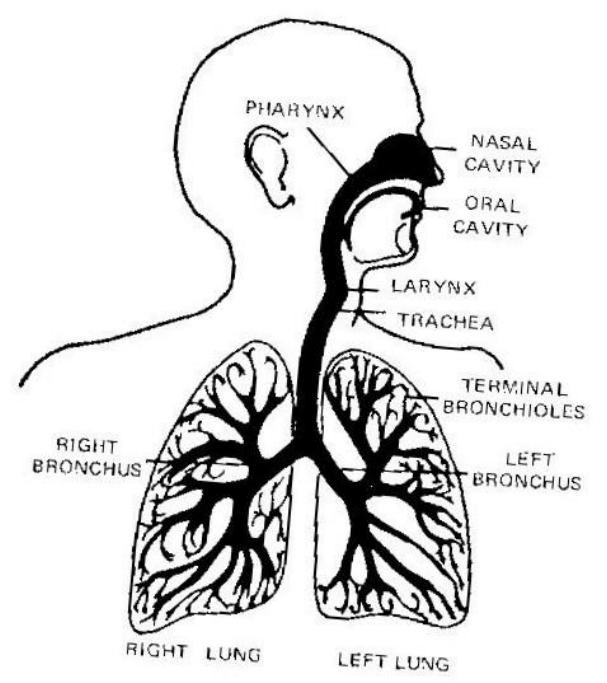

Figure 2 : The Major Features of the Human Respiratory System (National Air Pollution Control Administration, 1969) 
Cheng (Smith, Cheng, \& Yeh, 2001) studied the deposition of these fine particles in the nasal and tracheobronchial airways using sodium chloride aerosol particles and airway replica casts. There were human volunteer studies conducted to verify the results from the replica. The results from both the studies were similar suggesting that the deposition increases as the size of the particle decreases. Deposition in the alveolar region is of prime importance as it is the only non-ciliated portion of the lungs. Cilia acts as a natural cleaning system for the lungs by removing particles from it. However, the alveolar region is void of this cleaning system as gas exchange takes place in this region. Figure 3 shows the conventional representation of the alveolar region or the terminal bronchiole.

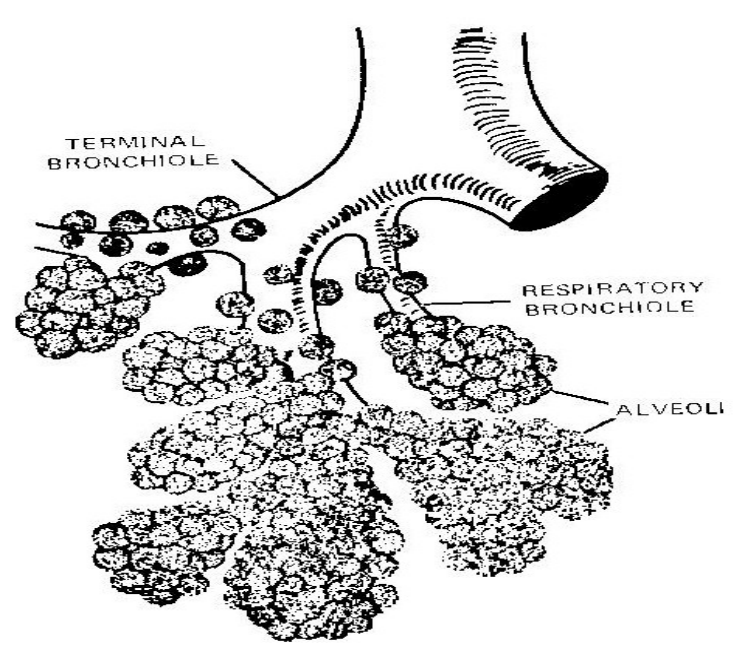

Figure 3 : Alveolar Region (National Air Pollution Control Administration, 1969)

The deposition of the ultrafine particles in the tracheobronchial or the alveolar region can result in three diseases - bronchitis, cancer, and asthma (Stern, Wohlers, Boubel, \& Lowry). Asthma is typically caused by the immune system reaction in which the airways narrow due to the tightness of muscles and swelling of tissue. The presence of hydrocarbons results in this reaction. The deposition of the particles in the airways make the hydrocarbons that are on the particle surface to completely soluble. This results in thinning the air passages of the immune 
system in order to restrict the amount of harmful hydrocarbons from entering the respiratory system. So the inhalation of PM can initiate asthma problems while worsening the preexisting condition.

The most dangerous disease associated to the PM is cancer (Hamra, Guha, Cohen, Laden, \& Raaschou-Nielsen, 2014) (Stern, Wohlers, Boubel, \& Lowry). The condensate which binds to the surface of the particles can solubilize. The cells which can be penetrated by particles attempt to repair the damage occurred but there is always a danger that some of the responses can be prone to error. The injured cells formed get divided and distributed due to the quickened division leading to DNA errors. This results in the improper functioning of the cells causing the cells to operate with the changed DNA and develop the tumors.

In these lung disorders, it's the individual's body response to the PM that leads to major disorders. So the short term exposure to these foreign particles may not be so dangerous to the health but the long term exposure can definitely have an influence on the body's natural defense mechanism. It can be to an extent that these reactions begin to harm rather than protect. Deposition of the PM can not only cause lung diseases but also can affect several other areas of the body (Lippmann, Gurman, \& Schlesinger, 1983). Macrophages in the alveolar region is responsible to digest these foreign bodies and clear them once every two months. However continual deposition in this region will lessen the efficiency of the macrophages to dissolve the particles. This will result in the toxic particles remaining deep in the lungs for long and the clearance can have undissolved particles which are transferred to other areas of the body through the blood to liver, kidneys, heart and brain (Stern, Wohlers, Boubel, \& Lowry). Many researches on the particulate matter are more concentrated on the size of the particle. However, it is important not to neglect on the mass of the particle which can also result in health disorders. The 
number, mass and size of particulate matter inhaled and retained have been shown in various studies (Strak, et al., 2012) (Hinds, 1999) linked with respiratory health effects. Hence it is clear that the three major arguments - mass, number and size need to be measured and studied together rather than conducting individual studies on each of them.

\subsection{Particle Formation and Measurement of Particle Number}

The important parameter based on which the Particulate Matter is qualified as a given type is the diameter value. The particle names based on diameter size $-D_{p}$ less than are large particles (PM10), $\mathrm{D}_{\mathrm{p}}$ less than $2.5 \mu \mathrm{m}$ are fine particles $(\mathrm{PM} 2.5), \mathrm{D}_{\mathrm{p}}$ less than $100 \mathrm{~nm}$ are ultrafine particles and $\mathrm{D}_{\mathrm{p}}$ less than 10nm are nanoparticles. The figure 4 below shows the classification of particles that are emitted from combustion engines based on diameter of the particles.

The composition, size and form of PM depends mainly on the location and temperature within the system where the particles are collected i.e., the cylinder, the exhaust system and the surroundings (Merkisz \& Pielecha, 2015).

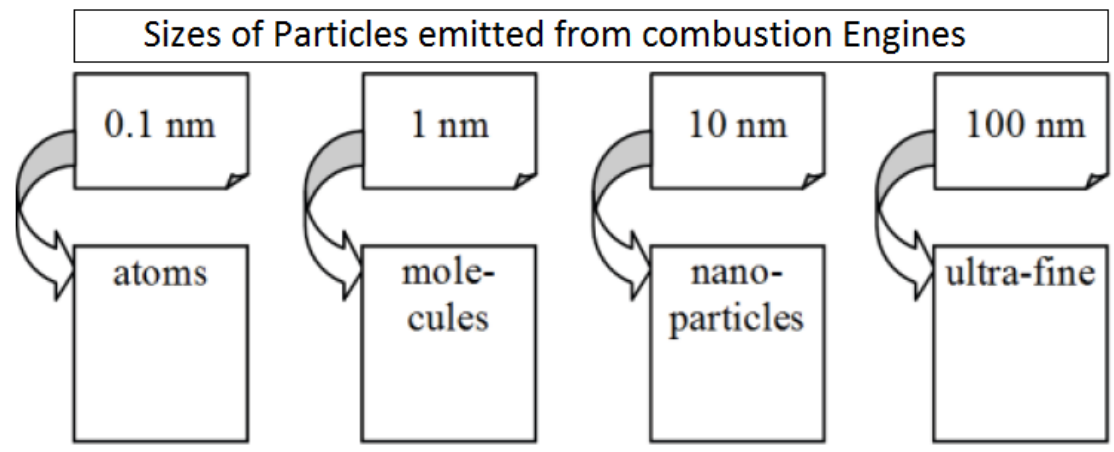

Figure 4 : Particles Classification Based on the Diameter Size (Dp)

Engines emit nanoparticles which are solid in nature, but do not directly emit volatile nanoparticles. The particles are formed as soon as the exhaust exits the engine and comes in contact with the atmosphere thereby undergoing dilution process. The volatile and semi volatile 
particles are formed from the organic and sulfur compounds in different stages namely nucleation, accumulation, agglomeration and condensation (Kittelson \& Khalek, Formation of Nanoparticles during Exhaust Dilution, 1999). Nucleation mode particles are usually volatile in nature with a diameter of about $2 \mathrm{~nm}$. The typical range of particles in this mode are $3-30 \mathrm{~nm}$. This mode usually contains most of the particle number but very little mass. These particles with very small diameter are very mobile (Brownian motion) and as a result they collide with each other to form larger particles of $30 \mathrm{~nm}$ to $500 \mathrm{~nm}$ aerodynamic diameter range (Kittelson D. , 2015) (Merkisz \& Pielecha, 2015). This stage is known as accumulation. The carbon atoms in these particles are ten times more than hydrogen atoms (Baron \& Willeke, 2001). The formation of these particles ensues in an increase in surface area which thereby results in agglomeration. Agglomeration is a combination of coagulation and aggregation. It involves creation of larger particles of smaller number by the process of colliding particles. The increase in the size of the particles depends mainly on their degree of agglomeration, which is affected by the initial number concentration of the particles and the coagulation time (Merkisz \& Pielecha, 2015). Table below summarizes the changes in the physical properties of these particles during different stages.

Table 3 : Changes in physical properties of solid particles (Fritz, 2012)

\begin{tabular}{|l|l|l|}
\hline \multicolumn{1}{|c|}{ Physical Effect } & \multicolumn{1}{|c|}{ Parameter Effected } & \multicolumn{1}{|c|}{ General Occurrence } \\
\hline Nucleation & Particle Number & Engine combustion chamber \\
\hline Agglomeration/coagulation & Surface area of particles & Engine exhaust system \\
\hline Diffusion/penetration & Change of mass & $\begin{array}{l}\text { Engine exhaust system, } \\
\text { collection of exhaust gas } \\
\text { sample }\end{array}$ \\
\hline Adsorption/condensation & Increase of mass & Dilution Tunnel \\
\hline
\end{tabular}


Most nanoparticles are formed by homogeneous nucleation of volatile particles as the exhaust dilutes and cools down. These nanoparticles constitute the majority of the total number of particles emitted by engines, but constitute to a very small part of their mass. The formation of these nanoparticles depends on factors like dilution rate, temperature, humidity and the concentrations of volatile and carbon matter (Kittelson \& Khalek, Formation of Nanoparticles during Exhaust Dilution, 1999). The study of these particle formation can only be done by accurate simulation of atmospheric dilution process in laboratory conditions.

The particles formed will have both solid and volatile fraction. According to the measurement requirements for particle number based on the regulations, only solid fraction of particles should be measured i.e. particles formed during accumulation phase. The main reason for this is the particles formed in nucleation phase are sensitive to the sampling conditions and also the tests performed on particles formed during accumulation phase are more repeatable (Merkisz \& Pielecha, 2015). Also it is difficult to determine repeatable conditions with nucleation phase particles as these are very sensitive to sampling conditions. The reason it is difficult to determine repeatable measurement conditions is they transform quickly when in contact with the atmosphere. So the sampling system for measuring particle number should consist of some arrangement to remove these volatile particles. Volatile compounds can be eliminated by means of dilution and thermal conditioning.

\subsection{PM Measurement Principle with Separation of Solid and Volatile}

\section{Fraction}

PM consists of solid and volatile fractions. Main challenge for the researchers is to come up with a sampling method to sample total particle size and number that represents atmospheric 
dilution process. As discussed in the previous sections, if volatile fraction is removed from the sample prior to the measurement then a high degree of accuracy can be achieved in measuring solid particle number and size. Previous studies (Suresh \& Johnson , 2001) (Venkatasubramaniam, 2007) indicate that particle growth is affected by large number of factors which include but not limited to, sampling system, dilution method, dilution ratio. Also at a regulatory stand point today for these engines $\mathrm{HC}+\mathrm{NOx}$ and $\mathrm{CO}$ emissions are being regulated. As volatile fractions are basically unburnt hydrocarbons which are being regulated there is necessity to try and understand what fraction of volatile compounds are emitted from these engines and to separate them while measuring for particulate matter emissions.

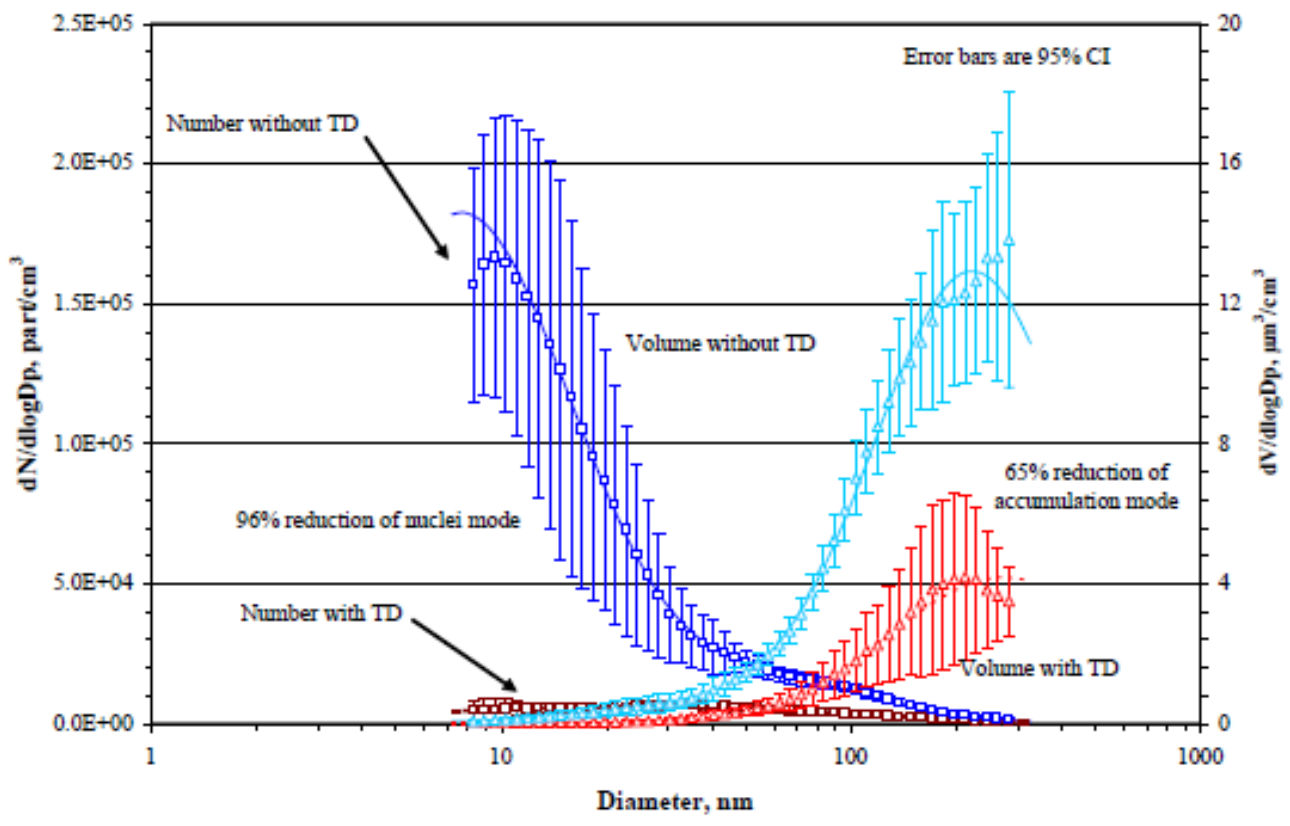

Figure 5: Separation of volatile particles using a thermal denuder in a study (Kittelson D. , 2015)

There are several methods to separate solid and volatile fractions. The two methods that are consistently used by researchers are thermal denuders and heat treatment. These two methods employed high temperatures which prevent nucleation. In thermal denuders method, the diluted engine exhaust is heated to high temperatures around $200{ }^{\circ} \mathrm{C}$ to $300{ }^{\circ} \mathrm{C}$ and then it is directed 
through a cooling section that contains adsorbing agent. Usually activated charcoal is used as an adsorbing agent. The volatile fraction in the gas phase is then adsorbed by this agent in this stage and therefore the measurements made after this stage implies only the solid fraction of PM. TSI Inc., Dekati Ltd. are examples of commercially available thermos denuders. Kittelson (Kittelson D. , 2015) performed a study on separation of volatile particle in diesel engines and was able to achieve $96 \%$ reduction in nuclei mode region and $65 \%$ reduction in accumulation mode region. It is clear that nuclei mode or nanoparticles are nearly all volatile. Figure 5 shows the results achieved in a study (Kittelson D. , 2015) to separate volatile particles by using thermal denuder.

The other method is by heat treatment of the sample before particle number counting. The system comprises of a vaporizing line and a diluter connected in series. The diluting is to reduce the number of solid particles in the sample that is entered into the system to be less that the upper limit of the counting system and also eliminating nucleation within the sample. 


\section{Experimental Setup and Test Procedures}

This study was done in CAFEE (Center for Alternate Fuels, Engines and Emissions) laboratory at WVU (West Virginia University). This facility is located in Morgantown, West Virginia. This chapter details about the dynamometer used, dilution systems, test engine, test cycle, instruments used for particle measurement and test procedure.

\subsection{Magtrol Dynamometer}

A Magtrol Hysteresis Engine Dynamometer ED-715-6N was used for this testing. These dynamometers have been designed to deal with severe, high vibration conditions in internal combustion engine testing and have high speed capabilities. The maximum rated torque is 55lb.in and maximum speed is $25,000 \mathrm{rpm}$. Torque and speed can be controlled manually or by PC, in this study it is controlled accurately by using a Magtrol controller. This dynamometer is cooled down by a blower for maximum heat dissipation. It has a large stainless shaft with additional front shaft bearing for greater support. Figure 6 shows the Magtrol hysteresis dynamometer used in this study and Figure 7 shows the Magtrol controller used to control this dynamometer

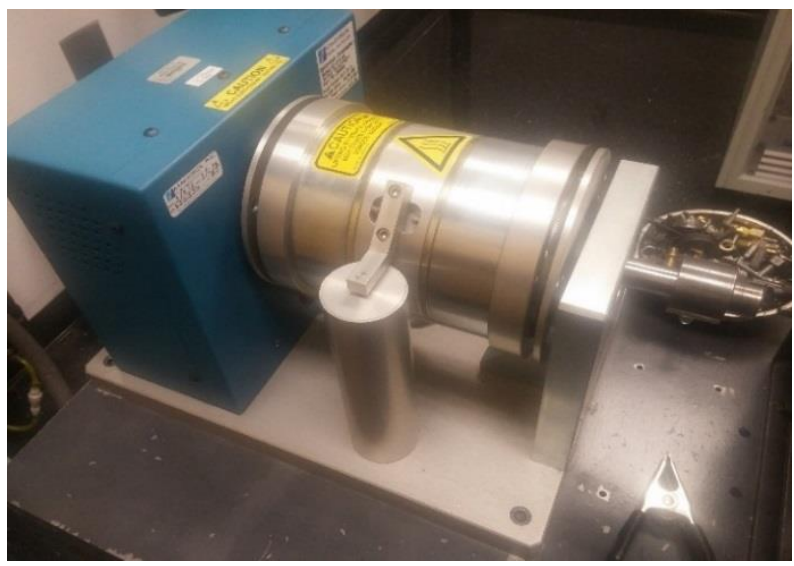

Figure 6 : Magtrol Hysteresis Dynamometer 


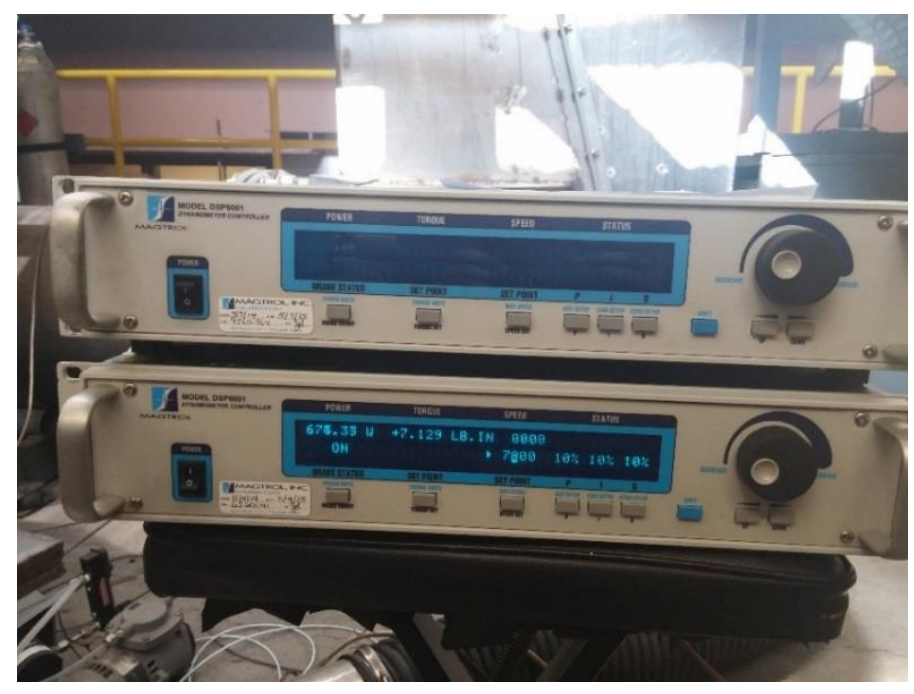

Figure 7 : Dynamometer Controller

\subsection{Dilution System}

\subsubsection{Constant Volume Sampling (CVS)}

Dilution systems are normally employed to simulate the atmospheric conditions and also to measure exhaust gaseous components both in particulate and gaseous form. Many methods are in existence by which dilution can be simulated, but certain standards have been set by USEPA in Code of Federal Regulations (CFR) Part 40. The system used for this test by CAFEE in WVU is the Subsonic Flow Venturi - Constant Volume Sampler (CVS). This system is in accordance with CFR Part 40. Figure 8 shows the picture of the CVS.

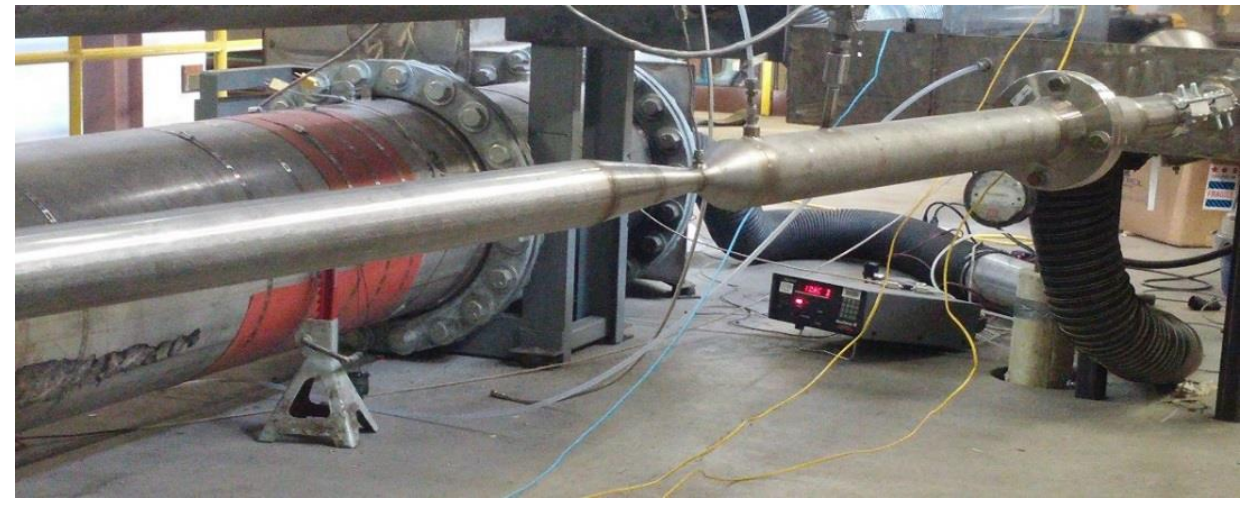

Figure 8 : Picture of CVS 
The CFR Part 40 states that the dilution tunnel should be built such that the dilution air and exhaust gas are completely mixed without adding or lowering the engine back pressure. Since the flow in tunnel should be turbulent $(\operatorname{Re}>4000)$, the diameter of the tunnel must be kept small and the length of the tunnel must be at least ten times the diameter to allow complete mixing of exhaust gas and dilution air before collecting any sample. The other requirement is there should not be any condensation taking place in the tunnel. Thus the temperature in dilution tunnel should be kept high. Also for electrostatic deposition not to occur in the tunnel, the tunnel should be fabricated by electrically conductive material and must be grounded.

The tunnel was constructed of stainless steel and is 4inch in diameter and sample was taken from sampling ports that were installed on the tunnel. The blower is used to draw the dilution air and exhaust. Dilution air is not heated and is filtered by using HEPA filters. Calibration checks on the tunnel were done as stated in the regulations CFR Part 40. A differential pressure gauge monitors the drop at the throat to insure subsonic flow at venturi. CFR Part 40 gives an equation for determining the molar flow rate as,

$$
\dot{\mathrm{n}}=C_{d} \cdot C_{f} \cdot \frac{A_{t} \cdot p_{\text {in }}}{\sqrt{Z \cdot M_{\text {mix }} \cdot R \cdot T_{\text {in }}}}
$$

Where,

$$
\begin{aligned}
& C_{d}=\text { discharge coefficient } \\
& C_{f}=\text { flow coefficient } \\
& A_{t}=\text { venturi throat cross-sectional area }\left(\mathrm{in}^{2}\right) . \\
& p_{\text {in }}=\text { venturi inlet absolute static pressure. }(\mathrm{psi}) \\
& Z=\text { compressibility factor. }
\end{aligned}
$$




$$
\begin{aligned}
& \mathrm{M}_{\text {mix }}=\text { molar mass of gas mixture. } \\
& \mathrm{R}=\text { molar gas constant. }\left(\mathrm{J} \cdot \mathrm{mol}^{-1} \cdot \mathrm{K}^{-1}\right) \\
& \mathrm{T}_{\text {in }}=\text { venturi inlet absolute temperature. }(\mathrm{K})
\end{aligned}
$$

\subsubsection{Second Stage Dilution - Dekati Diluter}

Second stage dilution systems apart from CVS dilution have been used by many research facilities to achieve high dilution ratios before sampling. Ejector type dilution system is one of different types used as second stage dilution. In this study a Dekati Diluter has been used.

Dekati diluter is robust, stainless steel construction which can withstand high temperatures is an excellent tool for aerosol dilution needs in research studies. Figure 9 shows the picture of Dekati diluter used for this study. The Dekati Diluter's operation principle is based on ejection dilution. Pressurized dilution air which is purified through HEPA filtration system flows at high speed around the ejector nozzle of the diluter causing a pressure drop which sucks in the exhaust sample through the nozzle automatically. In this diluter the exhaust sample is instantaneously diluted as it mixes with the air supplied, thereby providing a stable and homogeneous sample. The main advantage of using this type of ejector diluter is it only uses pressurized air for its operation thereby eliminating the need of flow devices or pumps. The operation of Dekati diluter is shown in figure 10. Some other features of Dekati diluters are even in continuous use it does not wear out, dilution factors up to 10000 can be achieved by connecting diluters in series, and less losses due to coaxial dilution. 


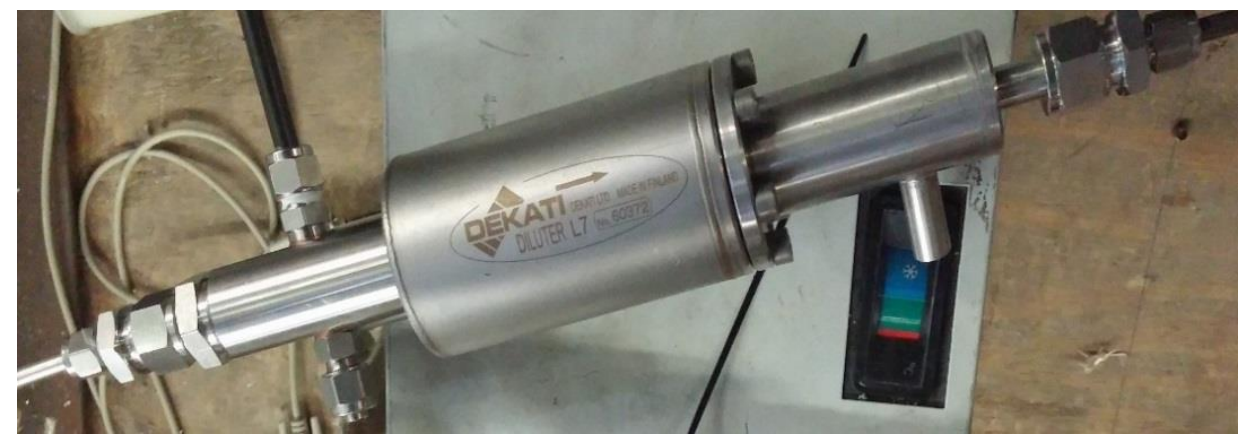

Figure 9 : Dekati Diluter

The nominal dilution factor of this diluter is 1:8 but is capable to be provided with different dilution factors. The dilution factor of the CVS used was approximately 1:10. The Dekati diluter-60372 was used in this study which provides a dilution factor of 1:8.32 when operated at 2 bar over pressure. So this diluter was connected in series with the heated line which samples out from the CVS and purified, compressed air at 2 bar pressure was supplied to diluter, to achieve a dilution factor of around 1:80 after the second stage of dilution. This made the sample to be in the range of instruments used for particle sizing and particle counting measurements.

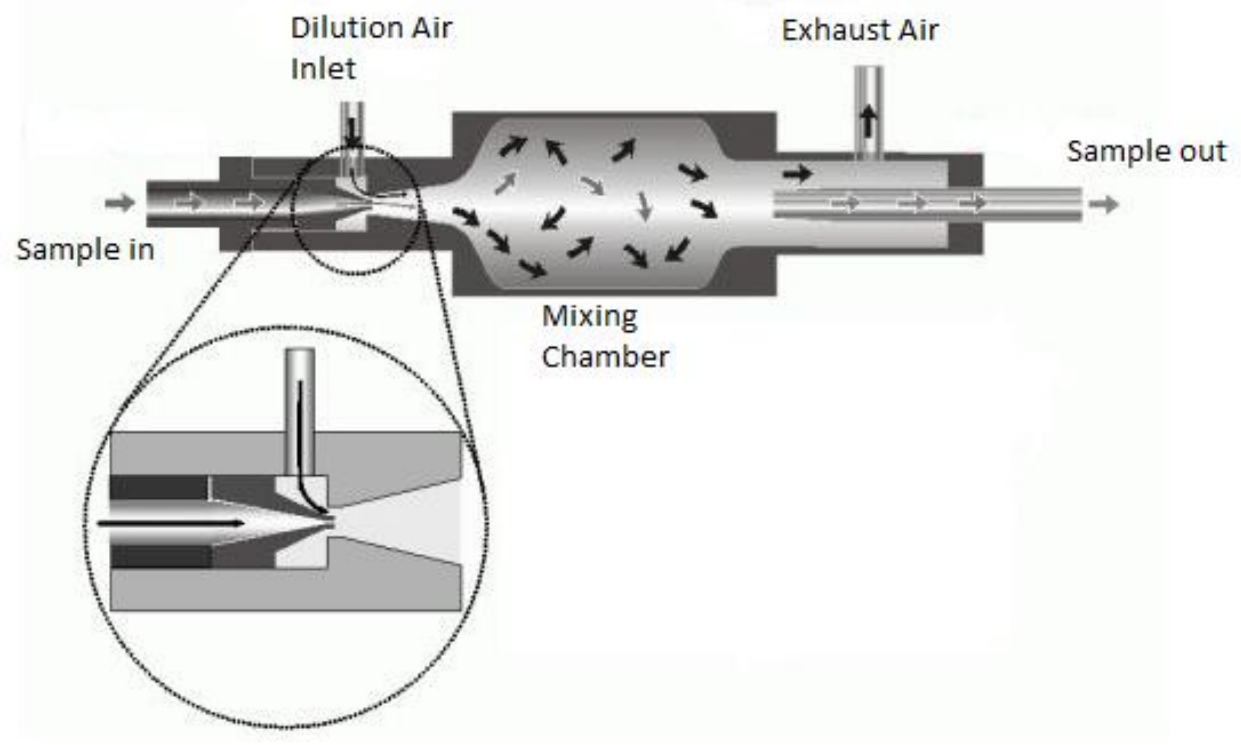

Figure 10 : Operation of Dekati Diluter (Dekati, 2016) 


\subsection{Particle Sampling System}

\subsubsection{Scanning mobility particle sizer (SMPS)}

The SMPS spectrometer is a key tool, widely used as the standard for measuring airborne particle size distributions. The sizing performed using this technique is discreet, where in the number concentrations of the sample are measured directly without assuming the shape of the particle size distribution. Figure 11 illustrates the setup of TSI's SMPS spectrometer employed in this study. The CPC and classifier are hardware interfaced with an analog BNC connector. DMA model 3081 was used to obtain a full particle size distribution, from $5.83 \mathrm{~nm}$ to $228.8 \mathrm{~nm}$. Model 3022A CPC, was used in this study.

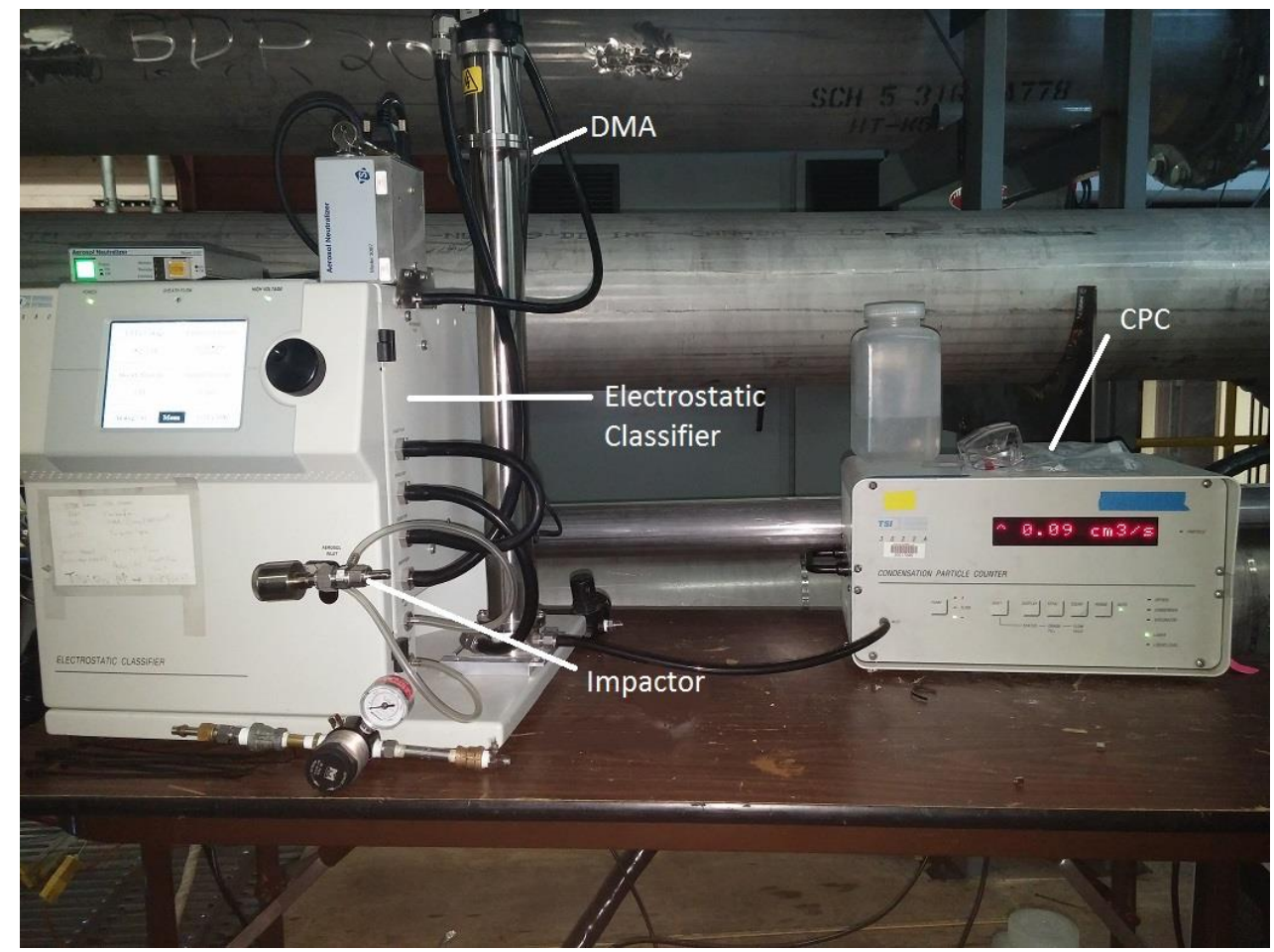

Figure 11 : Scanning Mobility Particle Sizer setup 


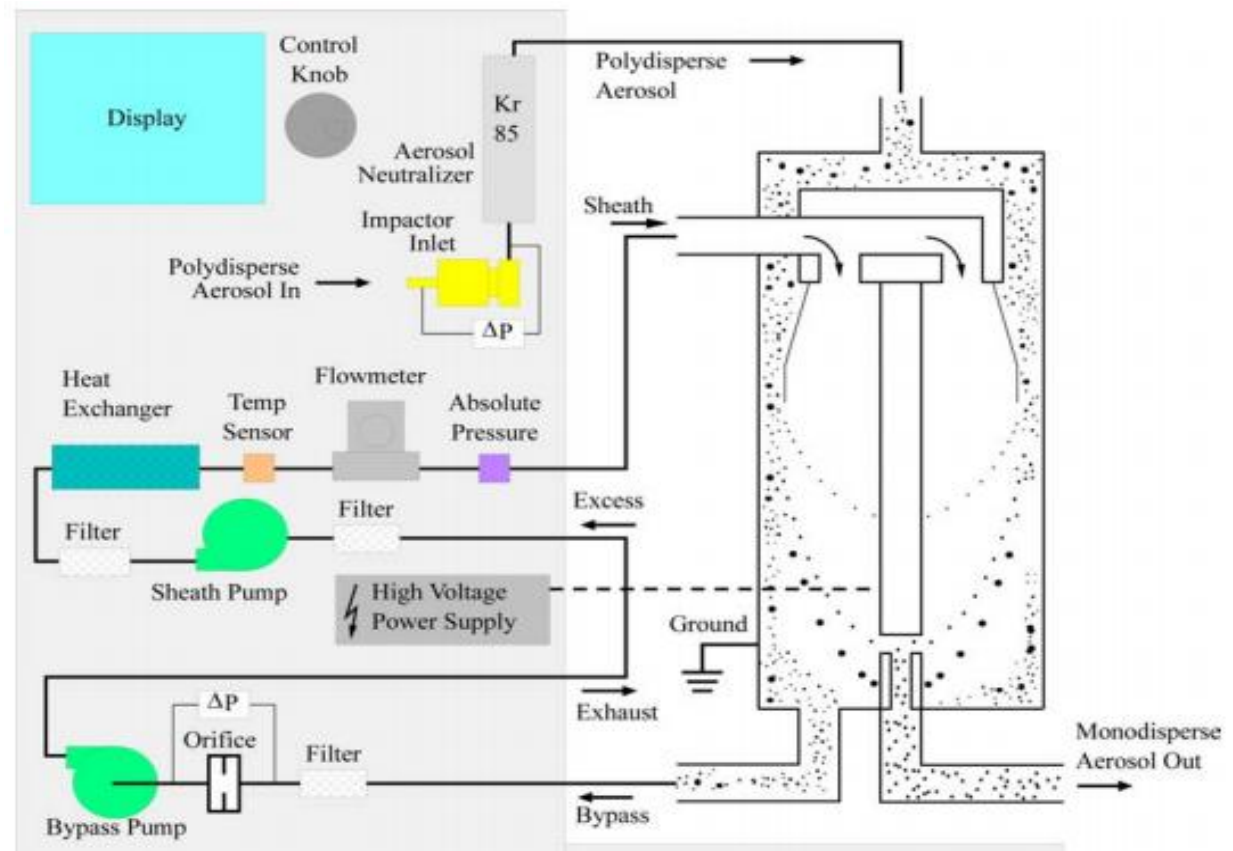

Figure 12: Schematic Flow Diagram of Classifier with DMA (TSI, 1999)

Briefly, the spectrometer consists of two major components, namely- mobility analyzer and condensation particle counter. The instrument measures the size distribution and therefore the concentration of the particles, using a technique known as Differential Mobility Analysis (DMA). This technique is based on the physical principle that the ability of a particle to traverse an electric field is related to its particle size. Figure 12 provides a schematic explanation to the working principle of the electrostatic classifier.

Figure 13 shows the schematic of the DMA. DMA operates by creating an electric field and further the airborne particles drift in the created field according to their respective electric mobility potential. The utilization of this phenomenon allows us to calculate the mobility distribution of the aerosol sample directly from the observed electric mobility diameter. Equivalent electric mobility diameter is considered to be a close approximation of the Stoke's diameter, calculated from the particle's density and settling velocity. Although the particle 
measurement techniques essentially involve the computation of both aerodynamic diameter as well as mobility diameter, here in this research it is important to understand that the use of aerodynamic diameter is almost trivial. Aerodynamic diameter is a representative for understanding more of a diffusional process, strongly influenced by density, and is of importance to process such as impaction or settling. Also, the density of particles, being typically less than 1 $\mathrm{g} / \mathrm{cm}^{3}$, the aerodynamic diameter is much less than that of the mobility diameter.

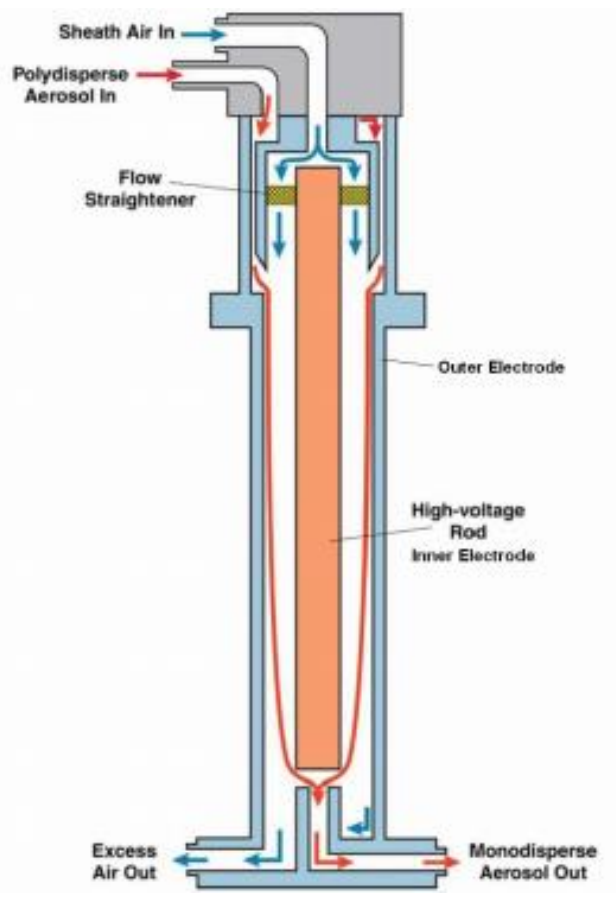

Figure 13 : Schematic of the differential mobility analyzer (DMA) (TSI, 1999)

By construction of the instrument, the aerosol to be analyzed first enters an impactor which removes particles larger than a given threshold size. This size selective removal mechanism has a cut point diameter $\left(50 \mathrm{~d}_{\mathrm{ac}}\right)$ which is a function of the nozzle diameter and flow rate. These two values are in tandem with the Stoke's number to calculate the $50 \mathrm{~d}_{\mathrm{ac}}$. The larger particles are therefore should to be removed because, they contribute negatively in terms of increasing the number of multiple charged particles. Once, the aerosol passes through the 
impactor, it enters the mobility analyzer. DMA is a cylindrical capacitor consisting of an inner electrode (high voltage rod) and an outer electrode (Figure 13.). The incoming sample flow containing the polydisperse aerosol is directed together with laminar particle-free sheath air parallel to the HV-Rod. The horizontal particle velocity is given by the expression:

$$
v=Z_{p} * E
$$

Where,

$$
\begin{aligned}
& \text { v- particle velocity, }(\mathrm{cm} / \mathrm{s}) \\
& Z_{\mathrm{p}} \text { - electrical mobility }\left(\mathrm{cm}^{2} / \mathrm{Vs}\right) \\
& \mathrm{E} \text { - Field strength }(\mathrm{V} / \mathrm{cm})
\end{aligned}
$$

Here, the electric mobility of a particle is defined as the ratio of the constant limiting velocity, a charged particle will reach in a uniform electric field to the magnitude of this field. As discussed earlier, the electric mobility depends mainly on the particle size and electric charge. The smaller the particle and/or the higher the electrical charge, the higher is the electrical mobility. The electric mobility depends on the particle diameter, $D_{p}$ given by

$$
Z_{p}=\frac{n e C}{3 \pi \mu D_{p}}
$$

Where,

$$
\mathrm{n} \text { - Number of elementary charges on the particle }
$$

$\mathrm{e}$ - Elementary charge $\left(1.6 * 10^{-19} \mathrm{C}\right)($ Coulomb)

C - Cunningham slip correction factor

$\mu$ - gas viscosity (g/cm.s)

$\mathrm{D}_{\mathrm{p}}$ - particle diameter $(\mathrm{cm})$ 
The range of these particle sizes removed by the DMA depends on the aerosol flow rate, mobility and the geometry of the concentric cylinders. Knutson (Knutson \& Lioy, 1995) gave an equation for electrical mobility which is

$$
Z_{p}=\frac{q_{s h}}{2 \pi V L} \ln \left(\frac{r_{2}}{r_{1}}\right)
$$

Where:

$$
\begin{aligned}
& \mathrm{q}_{\mathrm{sh}} \text { - sheath flow rate }(\mathrm{lpm}) \\
& \mathrm{r}_{1}-\text { inner radius of annular space }(\mathrm{cm}) \\
& \mathrm{r}_{2} \text { - outer radius of annular space }(\mathrm{cm}) \\
& \mathrm{V} \text { - Average voltage of collector rod }(\mathrm{V}) \\
& \mathrm{L}-\text { Characteristic length }(\mathrm{cm})
\end{aligned}
$$

From the above two equations, the diameter of the particles which exit the DMA can be computed as follows:

$$
D_{p}=\frac{2 n e V L C}{3 \mu q_{s h} \ln \left(\frac{r_{2}}{r_{1}}\right)}
$$

Before the particles enter the DMA, they pass through a neutralizer. The neutralizer does not neutralize charges, rather bring the particles into a well-known charge distribution with a radioactive polonium source. The result is a Boltzmann distribution of negative and positive charged particles. In an electric field a particle with ' $n$ ' charge experiences an electric force, causing it to move through the gas in which it is suspended. 
Once the aerosol exits the DMA, it enters the CPC. The Condensation Particle Counter (CPC) also called the condensation nucleus counter (CNC) is the most common instrument used to determine number concentrations of particles. Figure 14 illustrates the schematic operation of CPC. The aerosol upon entering the counter, passes over a heated pool of saturated butanol. This saturated aerosol then flows into a condenser where it is cooled by thermal diffusion process. The diffusion process allows the butanol to condense onto the particle surface, wherein they grow into droplets. This heterogeneous condensation is sustained through the presence of condensation nuclei in a saturated state. The saturation ratio, the partial vapor pressure divided by the saturation pressure, will decide the range of detectable particles, as described by the Kelvin equation:

$$
S=\exp \left[\frac{4 \sigma M}{\rho R T d^{*}}\right]
$$

Where,

$$
\begin{aligned}
& \mathrm{S} \text { - Saturation ratio } \\
& \sigma \text { - Surface tension }(\mathrm{N} / \mathrm{m}) \\
& \mathrm{M} \text { - Molecular weight }(\mathrm{g} / \mathrm{mol}) \\
& \rho-\text { Density of butanol }\left(\mathrm{g} / \mathrm{m}^{3}\right) \\
& \mathrm{R}-\text { Universal gas constant }\left(\mathrm{atm} \cdot \mathrm{m}^{3} /(\mathrm{mol} . \mathrm{K})\right) \\
& \mathrm{T}-\text { Absolute temperature }(\mathrm{K}) \\
& \mathrm{d}^{*} \text { - kelvin diameter }(\mathrm{m})
\end{aligned}
$$




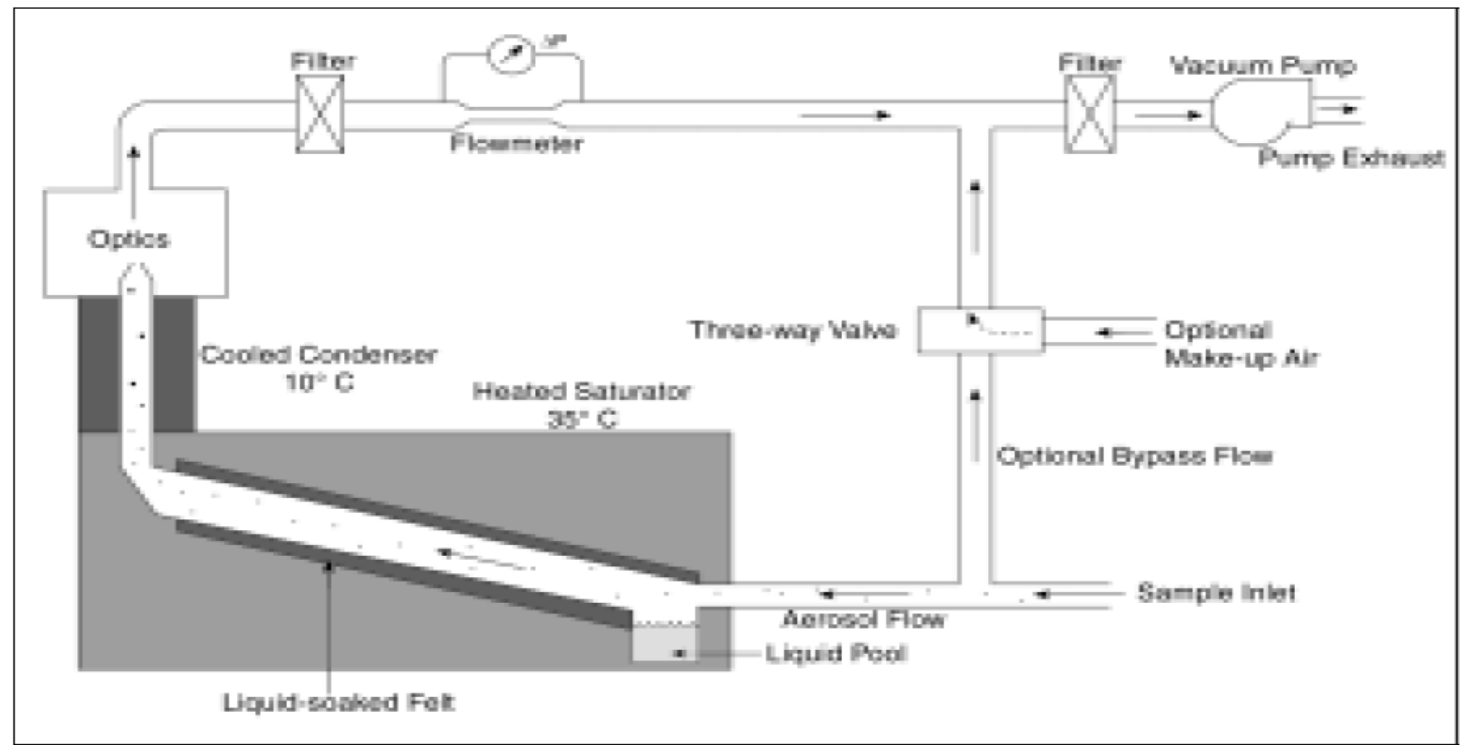

Figure 14: Schematic of CPC (TSI, 2002)

Particle size detection limit in the CPC is related to the increasing saturation ratio which is required with decreasing particle diameters. Modern CPCs have detection limits of around 10nm. CPC model 3022A uses real time counting in the situation where, as the concentration approaches the upper limit, the coincidence is automatically taken into account. The statistical errors also limit the accuracy of measurements at lower concentration levels. Ideally, the concentration should remain in the window, above $10 \%$ of the low end and below $10 \%$ of the high end, to minimize the statistical uncertainty and the coincidence.

The SMPS spectroscopy is independent of the refractive index of the particle or fluid, and therefore carries a tag of possessing high degree of absolute sizing accuracy at the same time ensuring good measurement repeatability.

In order to ensure good measurement accuracy, the SMPS was flow calibrated prior to the start of the experiment. Additionally, leak check checks were performed using, i) HEPA filter ii) zero voltage check. Characterized by its high filtration efficiency, the HEPA filter was 
connected to the inlet of the SMPS spectrometer, obtaining a full size scan. Leak checks also ensure that there are no particles which would be detected above the noise level of the instrument. In the second method, it was required that the voltage on the collector rod be set to zero and checked for any particles being detected. Since, the voltage on the collector rod determines the size of the particles that exit the classifier, a zero voltage on the rod would ensure that no particles exit the classifier. The inlet nozzle on the classifier was thoroughly cleaned with solvent such as alcohol, on a daily basis, which would remove the deposits obstructing the flow. A thin layer of vacuum grease ensured the minimization of particle bounce.

\subsubsection{Data reduction of SMPS and CPC}

In DMA, the particles are classified by corresponding size of the particles leaving the classifier to its proportional exponentially increasing voltage. These particles are then counted by $\mathrm{CPC}$ and the concentration values of each individual particle size are stored as raw counts in the PC. The particle size found from the raw data, believes a false assumption that each of the particle possess a single charge on them, even after passing through a bipolar charger. Multiple charges on a particle increase the mobility of the particles, which could be incorrectly stored into the smaller diameter range. Therefore, TSI uses an inbuilt algorithm in its proprietary SMPS software i.e., Aerosol Instrument Manager to correct for multiple charges, based on the aerosol charging theory proposed by Fuchs-Gunn. It is further corrected by a truncated triangular transfer function based on Knutson and Whitby. (TSI, 1999)

The proprietary software (Aerosol Instrument Manager) provided to record the CPC concentrations, does not automatically correct the data. So, transfer function, accounting for the efficiency of CPC and applying the correction for single particle charge has to be done. The final 
data for the SMPS was presented as particle size based concentration variation, computed with the concentration in normalized units of particles $/ \mathrm{cm}^{3}\left(\mathrm{dN} / \mathrm{d} \log \mathrm{D}_{\mathrm{p}}\right)$.

\subsection{Test Setup}

This study was done on a 2 cycle gasoline powered $25 \mathrm{cc}$ weed whacker engine manufactured by MTD Products. Table 4 shows the engine data. For this testing a new setup was built at the research facility in WVU. It was a closed box construction to make sure exhaust does not escape and was directed to the dilution tunnel. Once the engine is mounted on the dyno, the box was closed and sealed as shown in the figure 15, and thermocouples were placed at different positions to track temperatures at the engine cylinder head, four corners of the box setup, sparkplug temperature to make sure the engine is not over-heating. Figures 16 depicts the test bed setup. Maximum speed and maximum torque conditions are maintained by the Magtrol dynamometer (Figure 6). The fuel used in this testing was Craftsman 40:1 mix 2-cycle high performance fuel as recommended by the supplier. The fuel consumption was tracked using a weight scale.

Table 4 : Engine Data

\begin{tabular}{|c|c|}
\hline Displacement & 25cc \\
\hline Power & $0.97 \mathrm{hp} \mathrm{@8000} \mathrm{rpm}$ \\
\hline Rated speed & $8000 \mathrm{rpm}$ \\
\hline Idle speed & $3000 \mathrm{rpm}$ \\
\hline Mixture preparation & Carburetor \\
\hline Fuel & Craftsman 40:1 mix 2 cycle high performance \\
& fuel \\
\hline
\end{tabular}




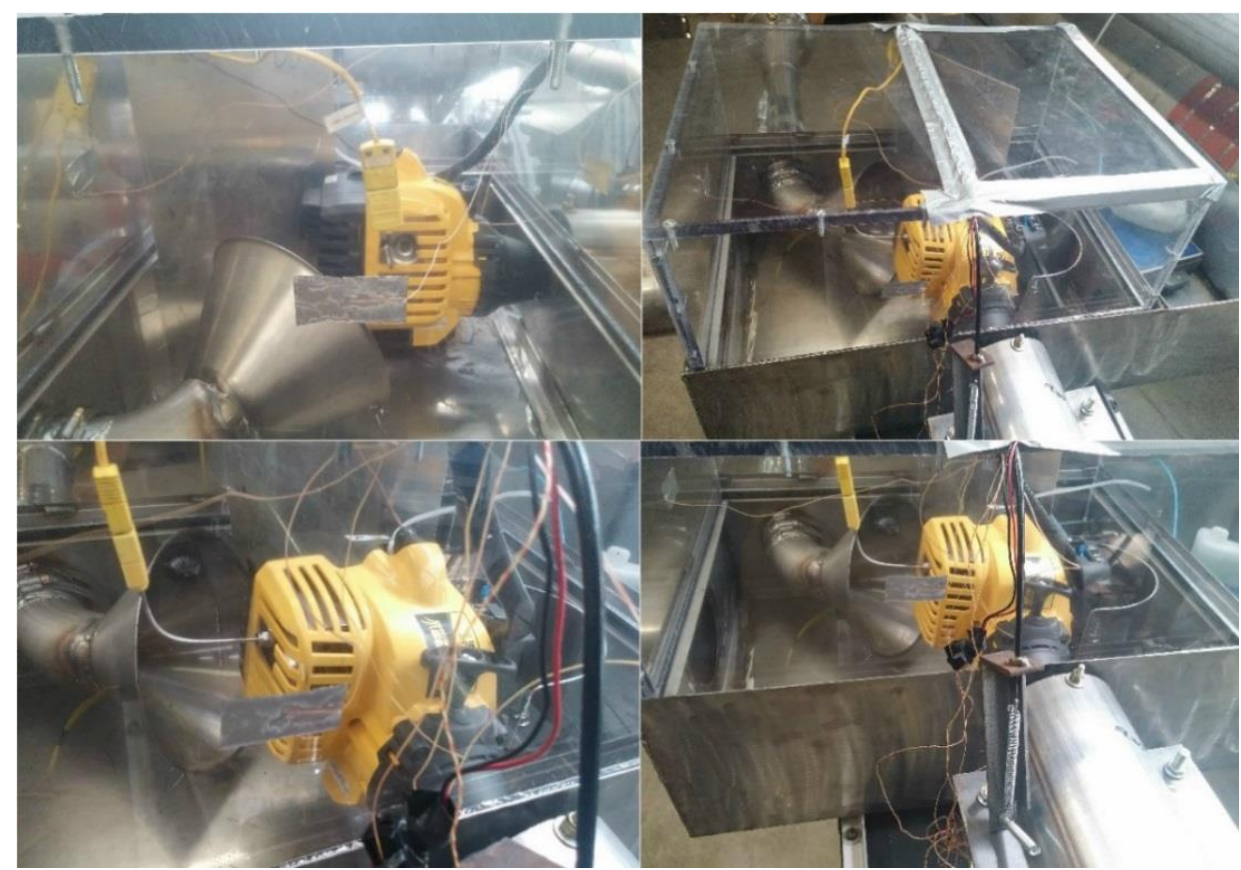

Figure 15 : Depiction of Engine Setup

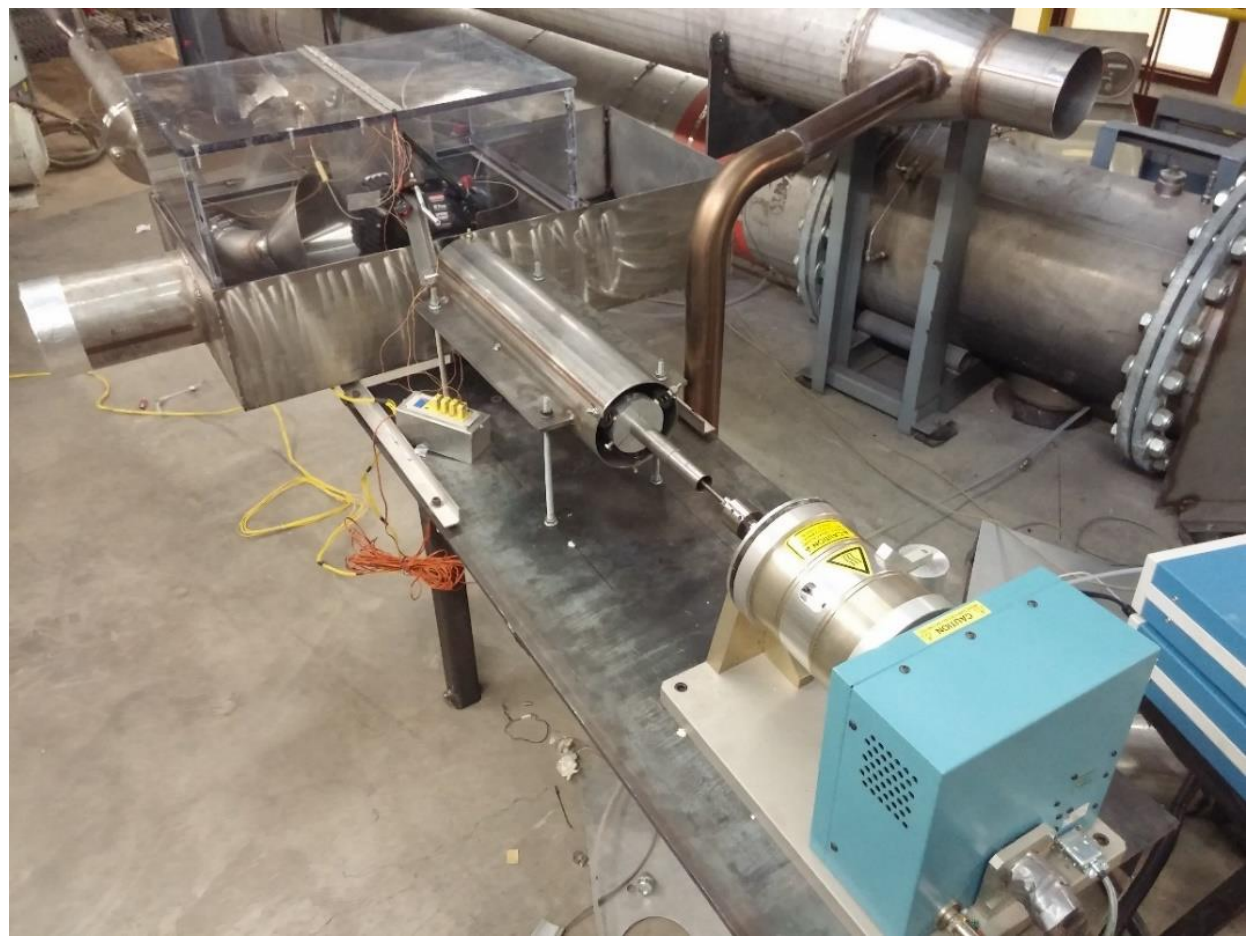

Figure 16: Depiction of Engine Setup on the Dyno

Sample was drawn from the tunnel through a J-probe which was inserted at a distance that would allow proper mixing of the exhaust with the dilution air. The sample drawn from this 
J-probe was directed into a heated manifold and then a $4 \mathrm{~m}$ long stainless steel heated line of quarter inch diameter for conditioning the sample to a certain temperature. Both the heated manifold and heated line were controlled by an omega controller. The omega controller was set accordingly to get desired sample temperature coming out of the heated line. The temperature of the sample is monitored at the end of a heated line by a thermocouple. The sample is then directed to a Dekati diluter for cold dilution. Dry and cold air is supplied at 2 bar pressure to the Dekati diluter. Before entering the diluter air is conditioned to remove any water particles by sending it through a HEPA filter and is then cooled by sending it through a chiller. The sample is then directed from Dekati diluter to the inlet of the SMPS for scanning. Figure 17 shows the schematic of the sampling system

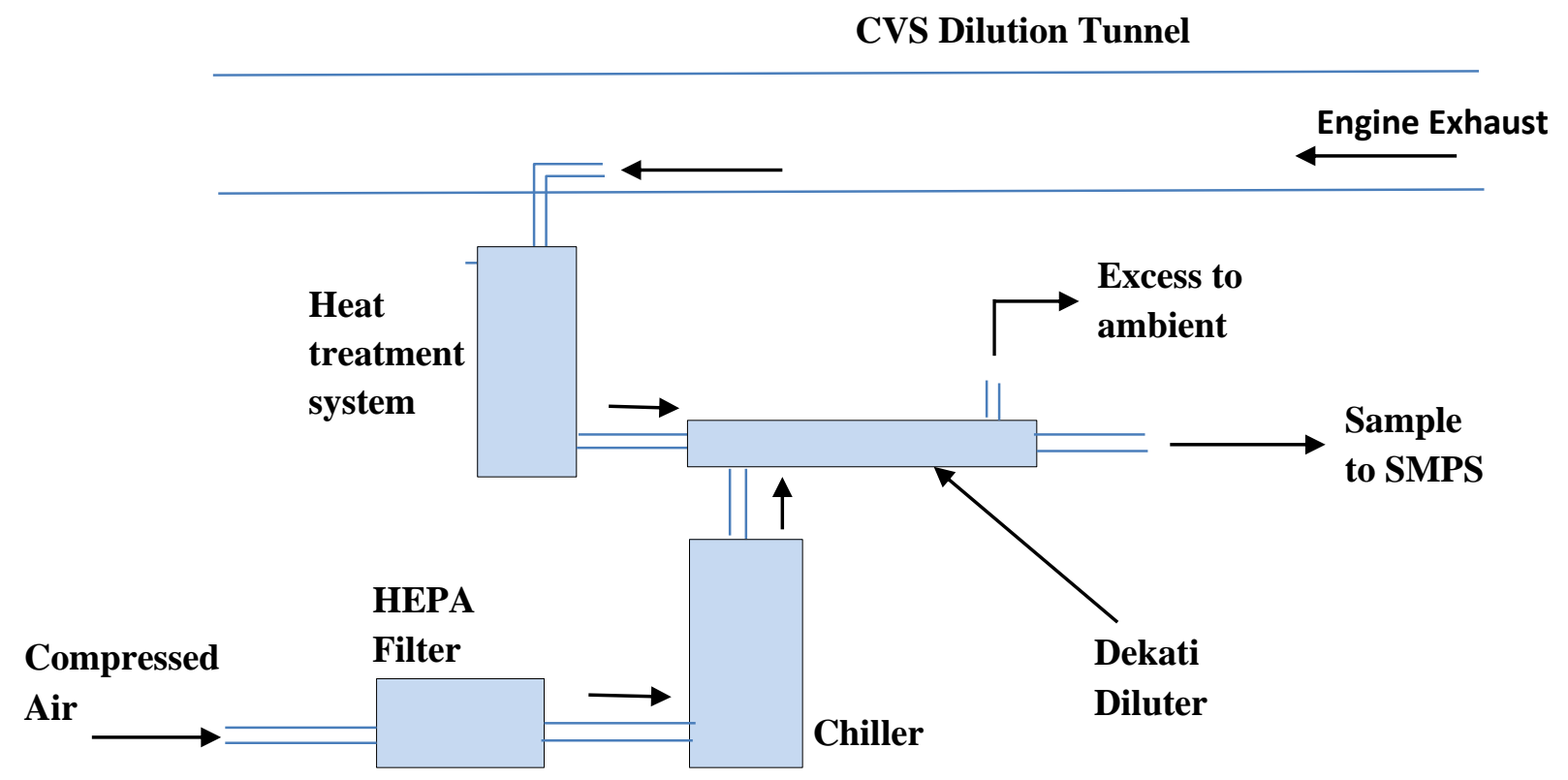

Figure 17: Schematic of sampling system. 
Before the actual test a pre-test run was done. During this pre-test it was checked if proper venturi nozzle was installed and the blower was maintained at the specific speed to ensure a steady operation. The engine was run at both WOT (wide open throttle) and idle throttle for warmup and to condition the tunnel before an actual test. After a ten-minute initial warmup actual test was started.

\subsection{Test Procedure}

This study employed a test procedure consisting of two modes derived from the Code of Federal Regulations for small handheld 2-stroke gasoline engines. These modes are - 1) WOT (wide open throttle) and 2) Idle.

The time taken by SMPS for one full scan of the sample was 165 seconds. More the scans per each sample and more the samples would result in better data. The WOT mode was run for 495 seconds to collect three samples with one scan each. The idle mode was extended to run two times longer i.e., 990 seconds to collect three samples with two scans each to facilitate better averaged data. The data is recorded in the SMPS software AIM (Aerosol Instrument Manager) for the two modes.

Data was collected in the SMPS for WOT and Idle mode at CVS and 3 different sample conditioning temperatures by varying the heated manifold and heated line temperatures in the omega controller. The heat treatment process to separate volatile and solid fractions involved the conditioning of the sample to 3 different temperatures $200{ }^{\circ} \mathrm{C}, 150{ }^{\circ} \mathrm{C}$, and $100{ }^{\circ} \mathrm{C}$. Due to equipment constraints the maximum temperature for conditioning attained was $200{ }^{\circ} \mathrm{C}$. The sample was first collected with conditioning temperature set at $200{ }^{\circ} \mathrm{C}$ which was followed by $150^{\circ} \mathrm{C}, 100^{\circ} \mathrm{C}$ and then sampled directly from the CVS as the heating process took more time heating up when compared to cooling down. For each mode before sampling at each 
conditioning temperature, sample drawn from the tunnel was sent directly to the SMPS for scanning to have more confidence that the engine was stable throughout all the tests. So a total of 16 test runs were performed for this study. Table 5 shows the test matrix which explains the order in which testing was done

Table 5: Test Matrix

\begin{tabular}{|c|c|}
\hline Mode & Sample Conditioning Temperature \\
\hline \multirow{4}{*}{ WOT } & $200{ }^{\circ} \mathrm{C}$ \\
\hline & $150^{\circ} \mathrm{C}$ \\
\hline & $100^{\circ} \mathrm{C}$ \\
\hline & CVS (exhaust sample temperature) \\
\hline \multirow{4}{*}{ Idle } & $200{ }^{\circ} \mathrm{C}$ \\
\hline & $150^{\circ} \mathrm{C}$ \\
\hline & $100^{\circ} \mathrm{C}$ \\
\hline & CVS (exhaust sample temperature) \\
\hline
\end{tabular}




\section{Results and Discussion}

This chapter presents the data collected from the tests and discusses the particle size distributions from the SMPS. The particle size distribution results from the SMPS were dilution ratio corrected. This chapter also shows the deviation between the mass results given by the SMPS software and the total mass calculated by Integrated Particle Size Distribution (IPSD) method.

\subsection{Particle size distribution results from SMPS}

The electrostatic classifier of the SMPS was operated at a sheath flow of $15 \mathrm{lpm}$ and sample flow of $1.5 \mathrm{lpm}$. In AIM software three samples data was collected for both modes at each sample conditioning temperature $\left(200{ }^{\circ} \mathrm{C}, 150^{\circ} \mathrm{C}, 100{ }^{\circ} \mathrm{C}\right)$ and the exhaust sample directly from the CVS which was then averaged for better analysis. The exhaust sample temperature was observed to be $70{ }^{\circ} \mathrm{C}$. The data collected in AIM was then exported and reduced to yield the particle size distributions at each condition.

These small engines are known for changing conditions that is shifting lean or rich after running for certain period of time. So to have a better validation of results an engine stability check was performed by collecting the samples in the CVS before each heat treatment test. Figures 18 shows the particle size distribution results for the sample collected in the CVS before each heat treatment test (CVS-200, CVS-150, CVS-100) at WOT mode and figure 19 shows the particle size distribution results for the sample collected in the CVS before each heat treatment test at idle mode (CVS-200, CVS-150, CVS-100). 


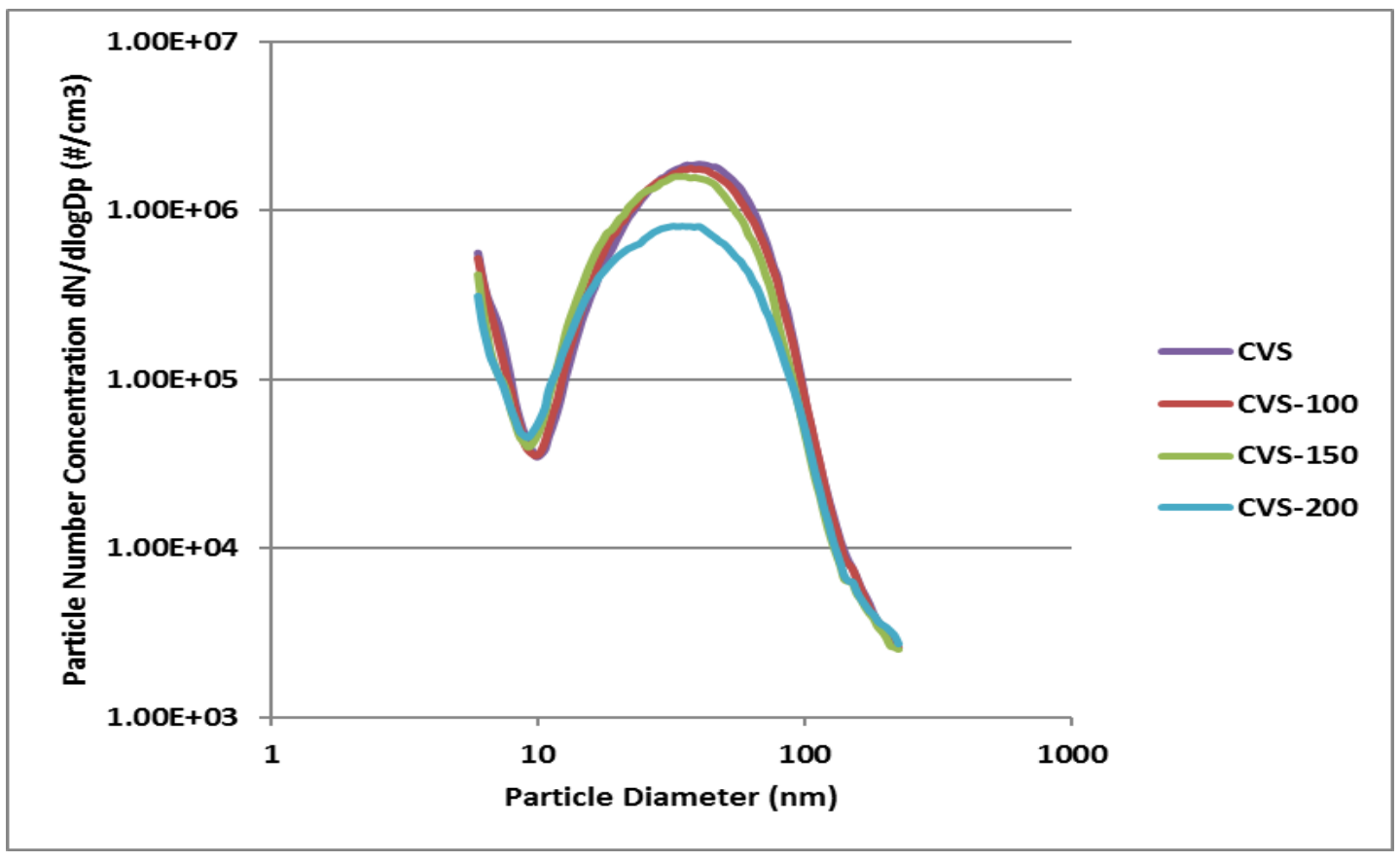

Figure 18: Particle size distribution of sample in CVS at WOT mode to check for engine stability

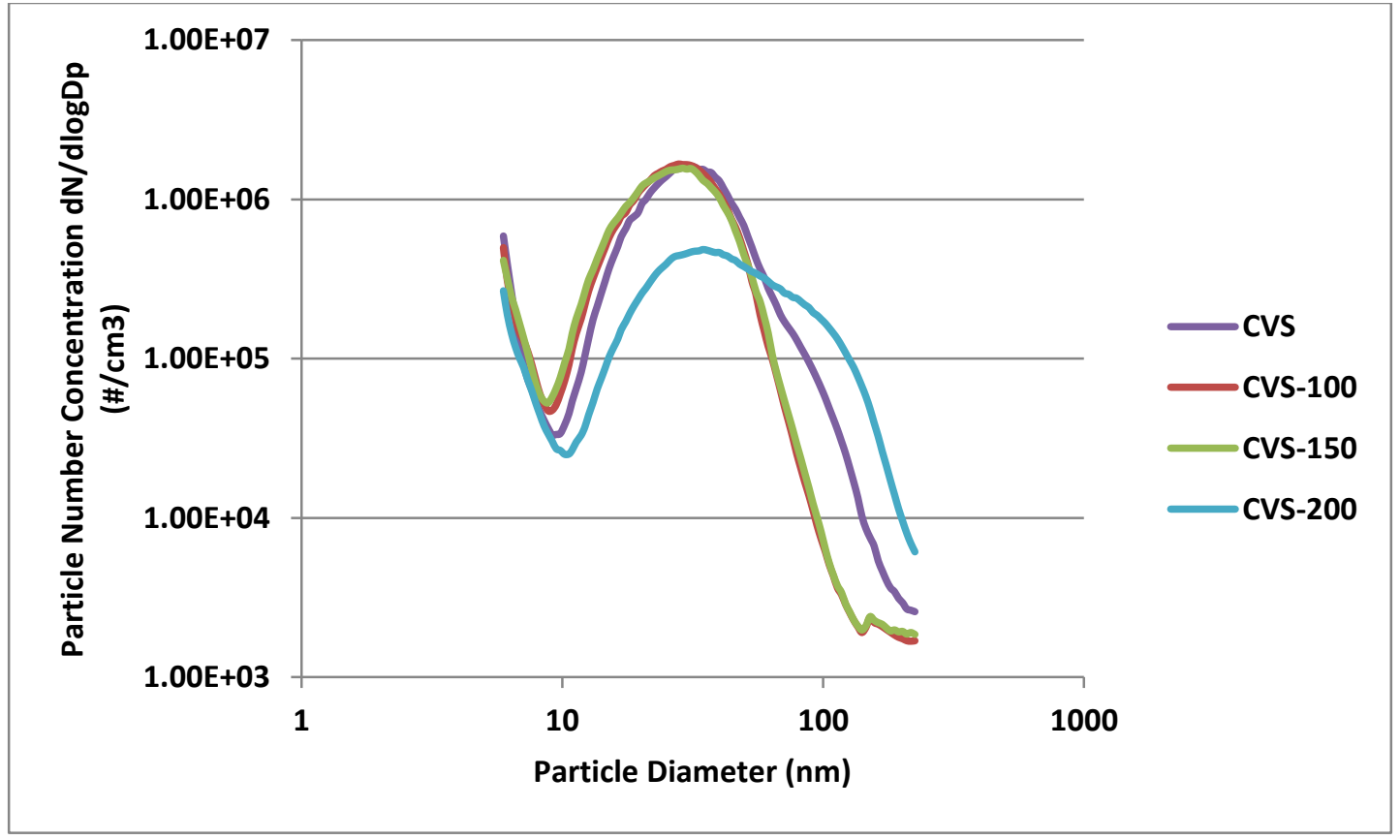

Figure 19: Particle size distribution of sample in CVS at Idle mode to check for engine stability

The particle size distributions in figure 18 and figure 19 shows the average of 3 SMPS scans at each stage and it was observed that the engine was very stable throughout all the tests 
except at first test of sample conditioning temperature of $200{ }^{\circ} \mathrm{C}$ which should be taken into consideration while analyzing the results at this stage. All the results provided by the SMPS have the tail on the left end of the particle size distributions. This is because of the artifacts from the X-ray source inside the SMPS.

Figure 20 shows the particle size distribution results at WOT and idle mode for the sample in CVS. The results shown at each mode in this figure are the average results of 3 SMPS scans. The error plots at each diameter indicate the minimum and maximum value obtained from those 3 SMPS scans. It is observed that the variation between each scan was high for WOT mode. This is because of the existence of volatile particles in the exhaust sample which do not have a fixed structure. It is also observed that the amount of volatile particles surrounding the solid core was high at WOT mode when compared to idle mode. The CMD at WOT mode was $32.2 \mathrm{~nm}$ compared to $31.1 \mathrm{~nm}$ at idle mode.

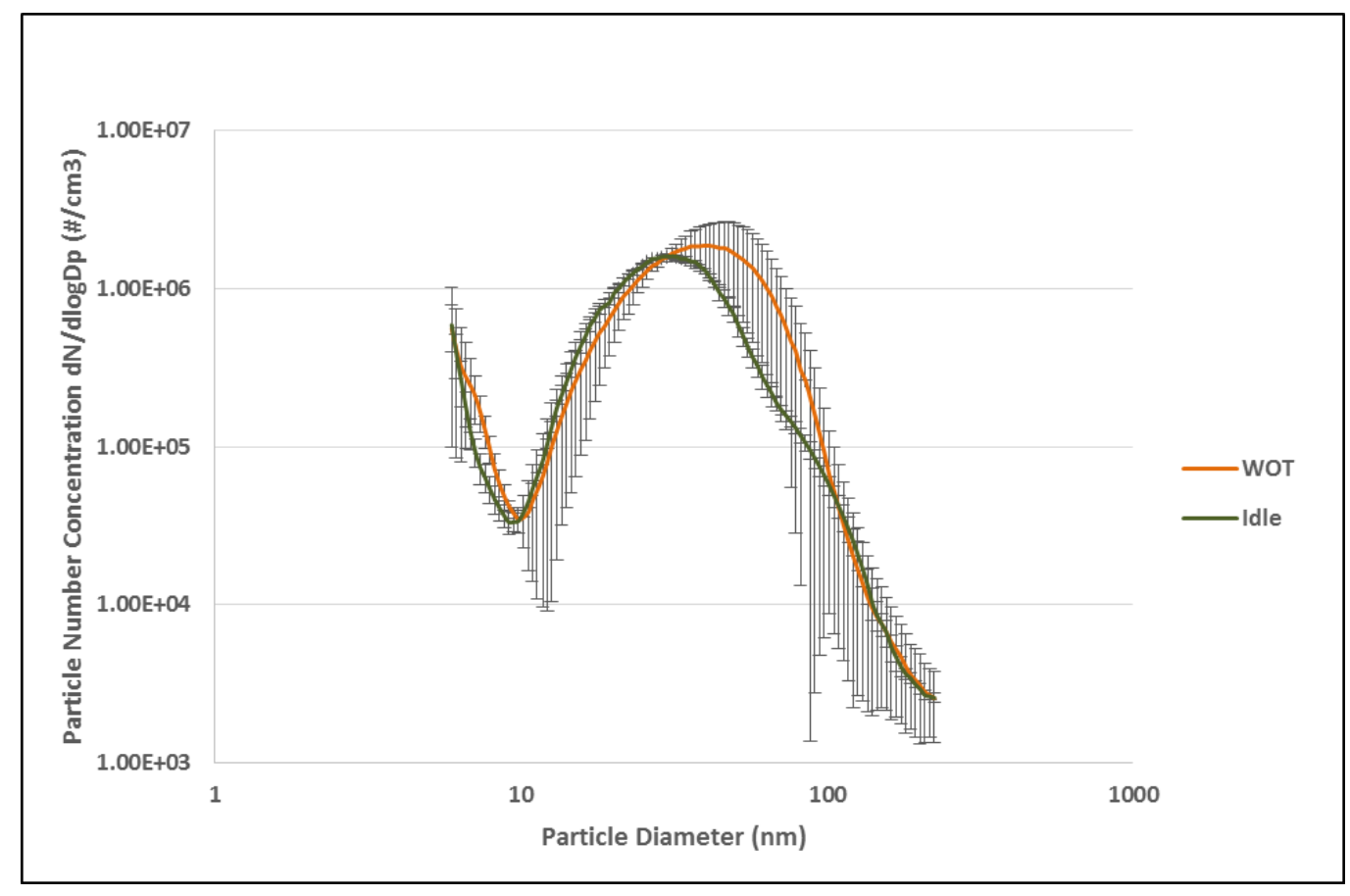

Figure 20: Particle Size Distribution by SMPS at WOT and Idle mode for sample in CVS 
Figure 21 shows the particle size distribution results at WOT and idle modes with sample conditioning temperature of $200{ }^{\circ} \mathrm{C}$ compared with the results of sample in CVS. The distribution results are the average of 3 SMPS. The error plots indicated that when the sample was conditioned before measuring for particle concentrations eliminated the volatile particle thus resulting in a very low minimum and maximum differences between the 3 SMPS scans thus indicating very repeatable measurement scans. This was the result expected when the sample is conditioned with heat treatment process, also, at this sample conditioning temperature idle mode had more amount of volatile particles than WOT mode surrounding the solid core of the particle. Maximum reduction of volatile particles was observed when compared to the sample in CVS. The CMD of particles was $14.1 \mathrm{~nm}$ at WOT and $23.3 \mathrm{~nm}$ at Idle mode compared to a CMD of $32.2 \mathrm{~nm}$ and $31.1 \mathrm{~nm}$ for the sample in CVS. The observed reduction in particle concentrations is due to the particle losses in the sampling system.

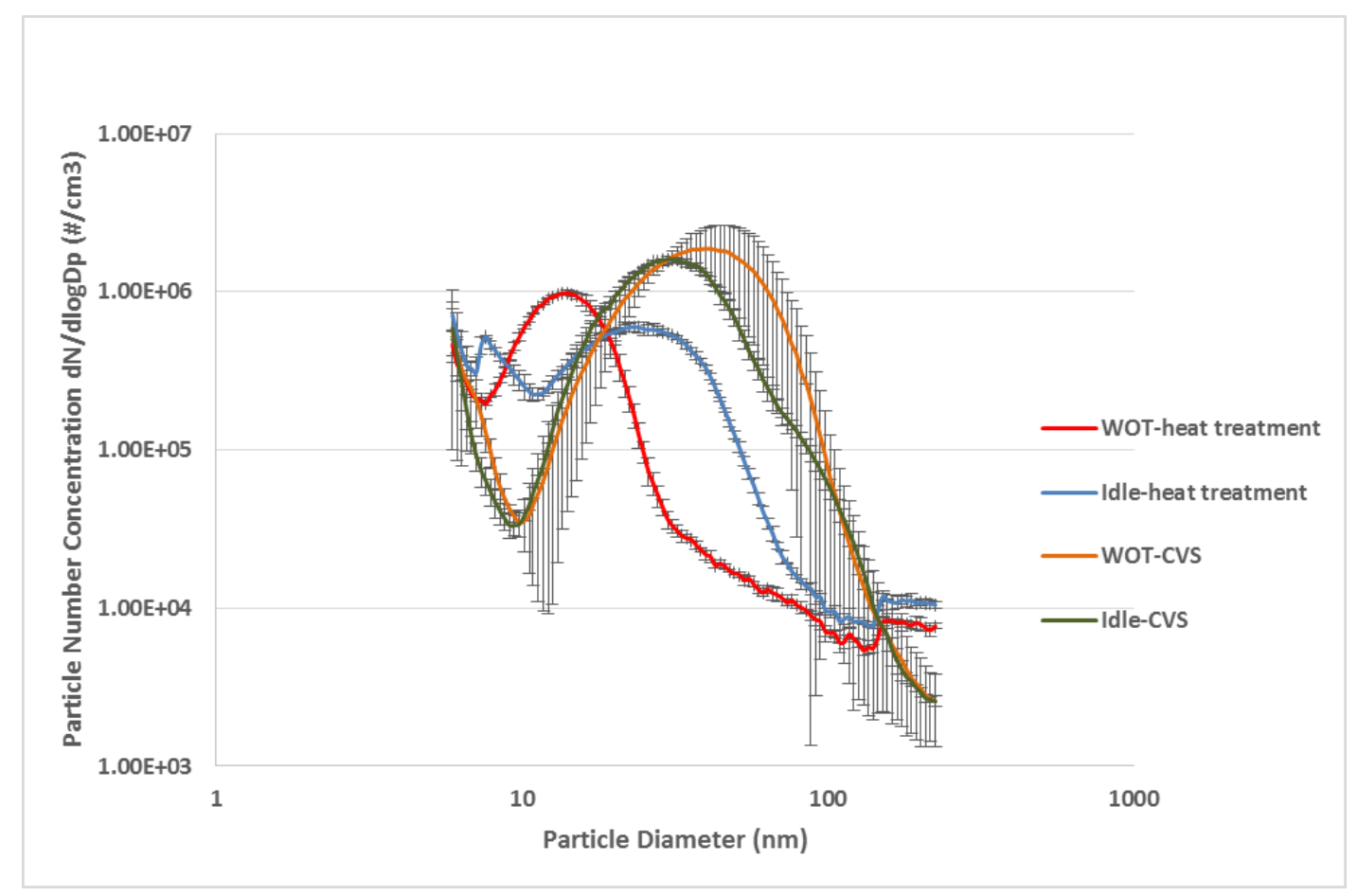

Figure 21: Particle Size Distribution at WOT mode and idle mode with Sample Conditioning Temperature of $200{ }^{\circ} \mathrm{C}$ compared with Sample in CVS 
Figure 22 shows the results of particle size distributions by SMPS for WOT and idle modes with sample conditioning temperature of $150{ }^{\circ} \mathrm{C}$ compared with the sample in CVS. Particle concentrations at WOT and idle mode at this sample conditioning temperature and the sample in CVS are in same order of magnitude. This indicates that there were very less particle losses during this test. Removal of volatile particles around solid core was observed even at this heat treatment condition when compared with the sample in the CVS. The CMD of the distribution at this sample conditioning temperature was observed to be $16.3 \mathrm{~nm}$ for WOT mode and $19.5 \mathrm{~nm}$ for idle mode compared to $32.2 \mathrm{~nm}$ at WOT and $31.1 \mathrm{~nm}$ at idle for the sample in CVS.

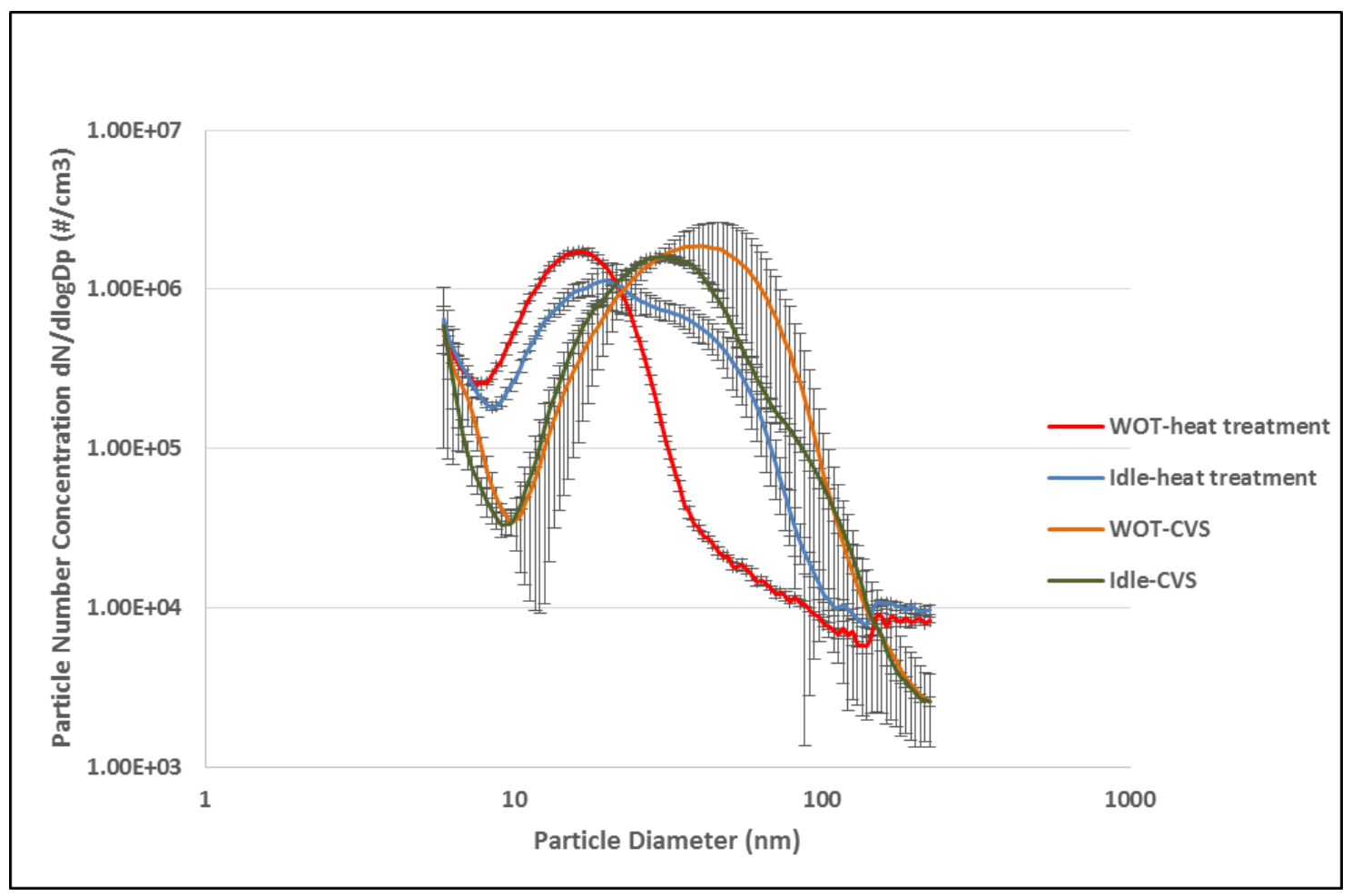

Figure 22: Particle Size Distribution at WOT mode and idle mode with Sample Conditioning Temperature of $150^{\circ} \mathrm{C}$ compared with sample in CVS 
Figure 23 shows the particle size distribution by SMPS for WOT and Idle mode with sample conditioning temperature of $100{ }^{\circ} \mathrm{C}$ compared with the sample in the CVS. It is known that the volatile organic compounds start to evaporate at different heat treatment temperatures depending on their composition. At this sample conditioning temperature, it is observed not much of volatile fractions were removed when compared with the sample in the CVS. The CMD of the distribution at this sample conditioning temperature was $28.9 \mathrm{~nm}$ at WOT and $30 \mathrm{~nm}$ at idle compared to $32.2 \mathrm{~nm}$ at WOT and $31.1 \mathrm{~nm}$ at idle for the sample in the CVS. Volatile particles do not have a fixed structure. This might be the possible reason for seeing an increase in the concentrations at this heat treatment temperature.

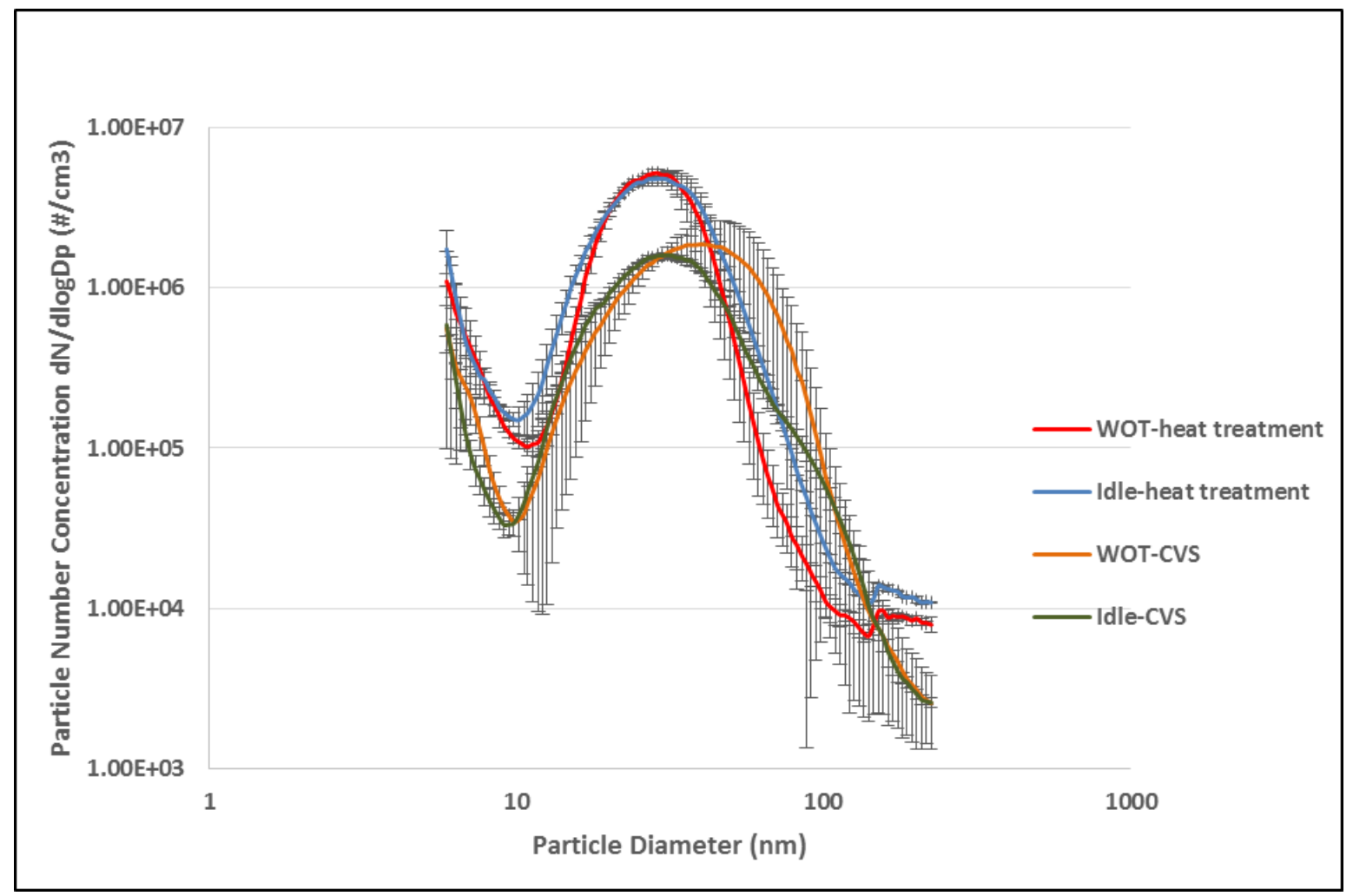

Figure 23: Particle Size Distribution at WOT mode and idle mode with Sample Conditioning Temperature of $100^{\circ} \mathrm{C}$ compared with sample in CVS 
Figure 24 and figure 25 show the averaged particle size distribution results from tests at WOT mode and idle mode with different sample conditioning temperatures compared to sample in CVS.

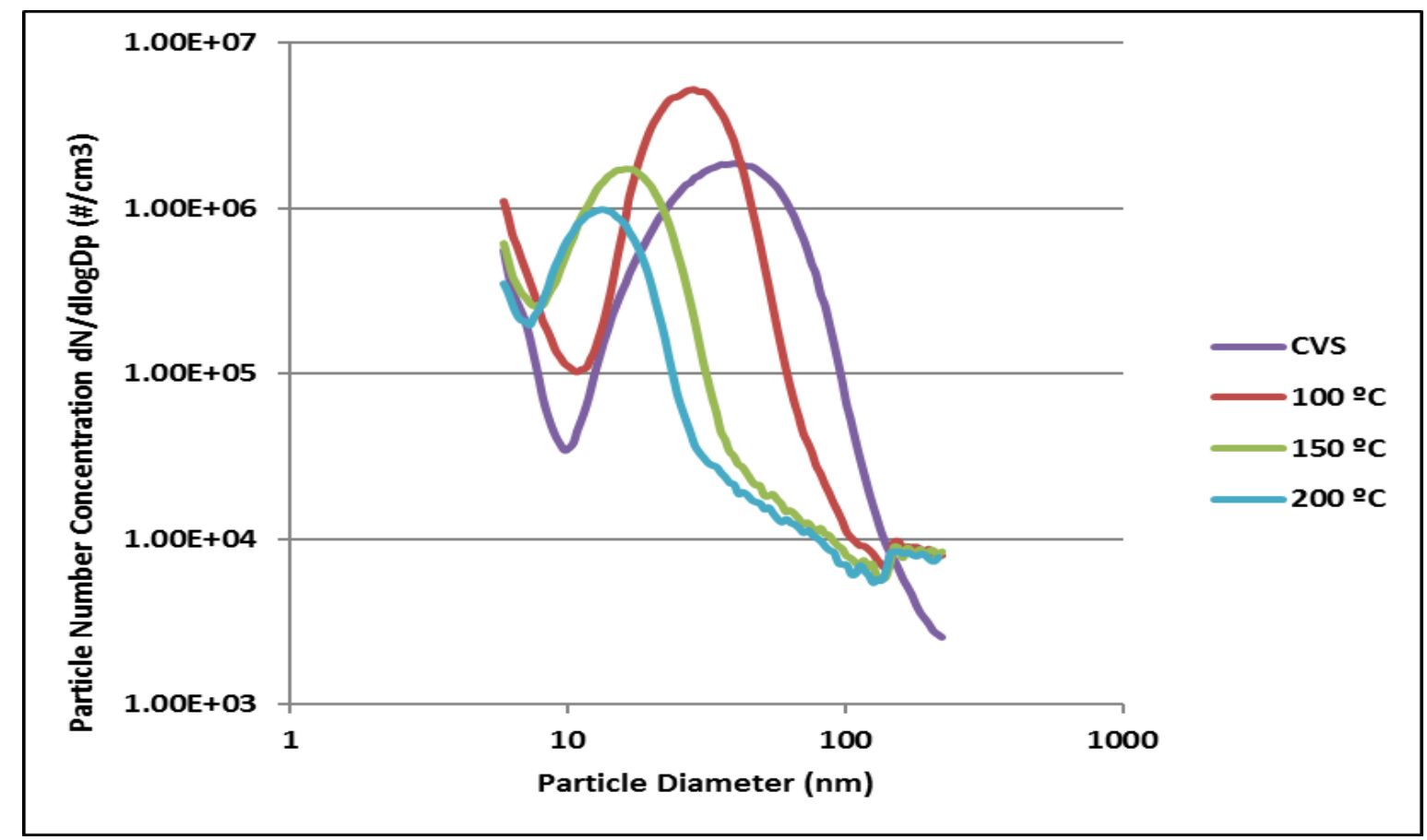

\section{Figure 24: Particle size distributions with different sample conditioning temperatures at WOT mode.}

The particle size distributions from figures 24 and 25 show that there is noticeable shift in the particle size diameters with heat treatment of the exhaust sample. This implies that there was good fraction of volatile particles present which was separated from solid core with the heat treatment of the sample. The sample from CVS lead to higher levels of volatile organic compounds as we expected to see and as the sample was conditioned during the heat treatment process showed that with increase in conditioning temperature the fraction of volatile compounds was reduced. In general, as the exhaust is cooled and diluted in the atmosphere these volatile compounds may adsorb sulfuric acid and/or undergo homogeneous nucleation to form particles. 


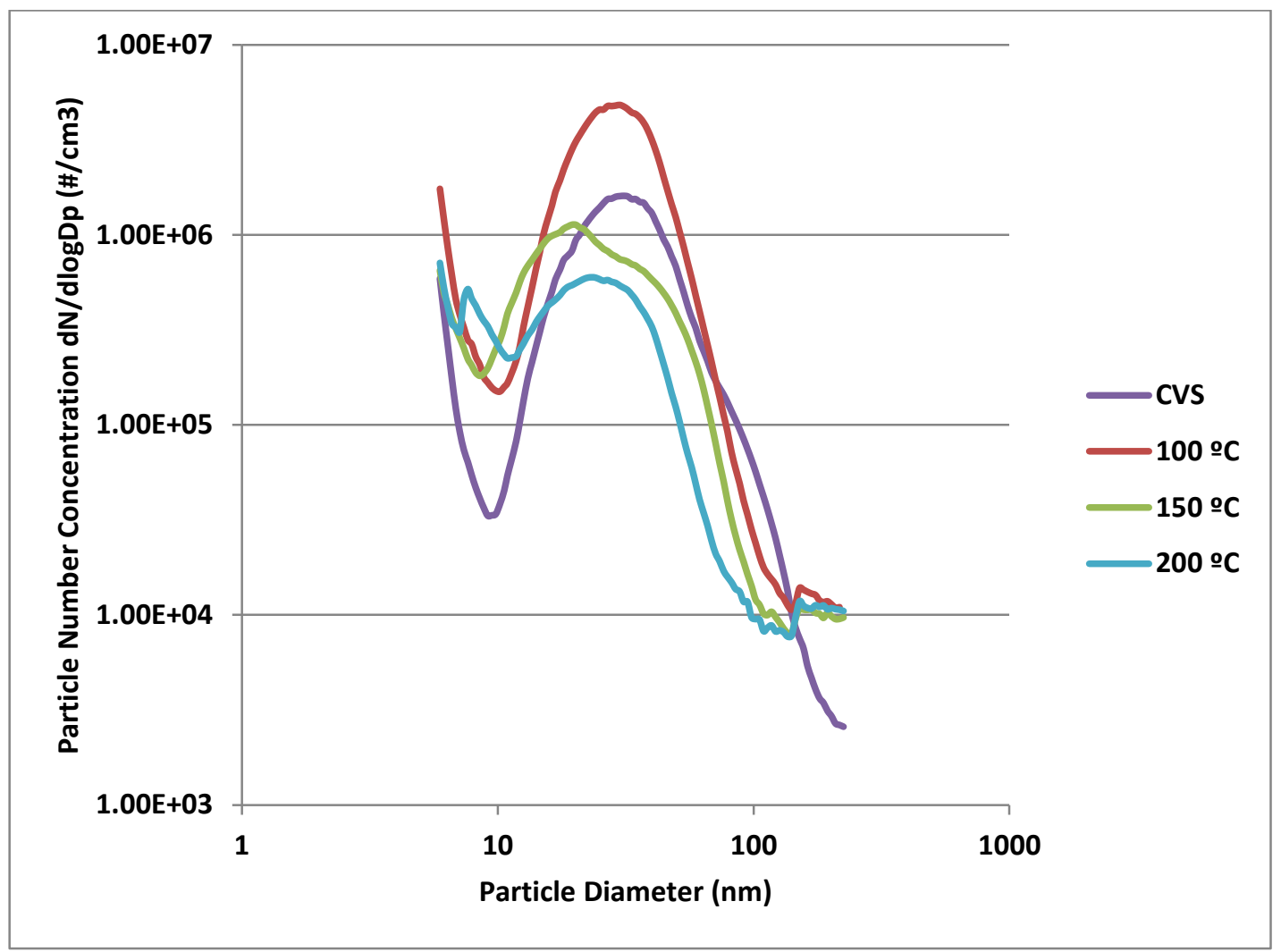

Figure 25: Particle size distributions with different sample conditioning temperatures at idle mode.

Tables 6 and 7 below show CMD (count Median Diameter) and GSD (Geometric standard Deviation) of the distributions at different temperatures both at WOT mode and idle mode. The geometric standard deviation for each distribution represents the distance of shift from the mean of the whole distribution and count median diameter gives the particle size with maximum concentration.

For WOT mode, the CMD for sample temperature with no additional heating was $32.2 \mathrm{~nm}$ with total concentration of $1.61 \times 10^{6}$ particles/cc. The CMD for exhaust sample temperature at $100{ }^{\circ} \mathrm{C}$ was $28.9 \mathrm{~nm}$ with a total concentration of $5.21 \times 10^{6}$ particles/cc. The CMD for exhaust 
sample temperature at $150{ }^{\circ} \mathrm{C}$ was $16.3 \mathrm{~nm}$ with a total concentration of $1.72 \times 10^{6}$ particles/cc. The CMD for exhaust sample temperature at $200{ }^{\circ} \mathrm{C}$ was $14.1 \mathrm{~nm}$ with a total concentration of $9.82 \times 10^{5}$ particles/cc. This drop in concentration could be attributed to the particle losses in the sampling system. It was observed that as the sample was heat treated with increasing temperature the volatile fraction was removed and the CMD was low at a conditioning temperature of $200{ }^{\circ} \mathrm{C}$ compared to the sample in CVS.

Table 6: CMD and GSD of particle size distributions at WOT mode

\begin{tabular}{|c|c|c|}
\hline $\begin{array}{c}\text { Particle Size Distribution } \\
\text { Sample Conditioning } \\
\text { Temperature }\end{array}$ & CMD (nm) & GSD \\
\hline CVS & 32.2 & 1.69 \\
\hline $100 \mathrm{C}$ & 28.9 & 1.53 \\
\hline $150 \mathrm{C}$ & 16.3 & 1.52 \\
\hline $200 \mathrm{C}$ & 14.1 & 1.57 \\
\hline
\end{tabular}

For Idle mode, the CMD for sample temperature with no additional heating was $31.1 \mathrm{~nm}$ with total concentration of $1.60 \times 10^{6}$ particles/cc. The CMD for exhaust sample temperature at $100{ }^{\circ} \mathrm{C}$ was $30 \mathrm{~nm}$ with a total concentration of $4.83 \times 10^{6}$ particles/cc. The CMD for exhaust sample temperature at $150{ }^{\circ} \mathrm{C}$ was $19.5 \mathrm{~nm}$ with a total concentration of $1.13 \times 10^{6}$ particles/cc. The CMD for exhaust sample temperature at $200{ }^{\circ} \mathrm{C}$ was $23.3 \mathrm{~nm}$ with a total concentration of $5.98 \times 10^{5}$ particles/cc. The results for distributions at a sample conditioning temperature of 200 ${ }^{\circ} \mathrm{C}$ show a higher $\mathrm{CMD}$ compared to $\mathrm{CMD}$ of the distribution at $150{ }^{\circ} \mathrm{C}$. This is likely due to the 
unstable engine conditions when sample was taken at $200{ }^{\circ} \mathrm{C}$ compared to other tests which was evident from figure 19.

The GSD for the particle size distributions at WOT mode and sample temperatures at no heat, $100{ }^{\circ} \mathrm{C}, 150{ }^{\circ} \mathrm{C}$ and $200{ }^{\circ} \mathrm{C}$ were $1.69,1.53,1.52,1.57$ respectively. The GSD for the particle size distributions at idle mode and exhaust sample temperatures at no heat, $100{ }^{\circ} \mathrm{C}, 150$ ${ }^{\circ} \mathrm{C}$ and $200{ }^{\circ} \mathrm{C}$ were $1.67,1.62,1.80,1.92$ respectively.

Table 7: CMD and GSD of particle size distributions at idle mode

\begin{tabular}{|c|c|c|}
\hline $\begin{array}{c}\text { Particle Size Distribution } \\
\text { Sample Conditioning } \\
\text { Temperature }\end{array}$ & CMD (nm) & GSD \\
\hline CVS & 31.1 & 1.67 \\
\hline $100 \mathrm{C}$ & 30 & 1.62 \\
\hline $150 \mathrm{C}$ & 19.5 & 1.80 \\
\hline 200 C & 23.3 & 1.92 \\
\hline
\end{tabular}

\subsection{Integrated Particle Size Distribution (IPSD) method}

The density function used by SMPS for calculating mass values doesn't take particle diameter in to consideration. So these mass calculations have to be validated. The particle number data given by the particle sizer may be converted to a mass data using a density distribution, which can be integrated to find out the total mass of the particles emitted. This type of measurement technique is called as Integrated Particle Size Distribution (IPSD) (Gerald Liu, Vasys, \& Dettmann, 2009). At low emission levels the mass measurements were consistent but at ultra-low emission levels IPSD method was one of the methods which proved to give more 
precise results. The Maricq's density distribution was found to be yielding accurate results when used in IPSD method (Gerald Liu, Vasys, \& Dettmann, 2009). Figure 26 shows the effective particle density curve compared with SMPS.

$$
\rho_{\text {eff }}=1.2378 \cdot e^{-0.0048 D_{p}}
$$

Where,

$$
\rho_{\text {eff }} \text { - effective density }
$$

$$
D_{p} \text { - effective diameter of the particle }
$$

The total mass for the IPSD method is calculated using the following equation (Gerald Liu, Vasys, \& Dettmann, 2009)

$$
M_{I P S D}=\sum_{i} \rho_{e f f, i} \cdot\left(\frac{4}{3} \pi \cdot\left(\frac{D_{p, i}}{2}\right)^{3}\right) \cdot n_{i}
$$

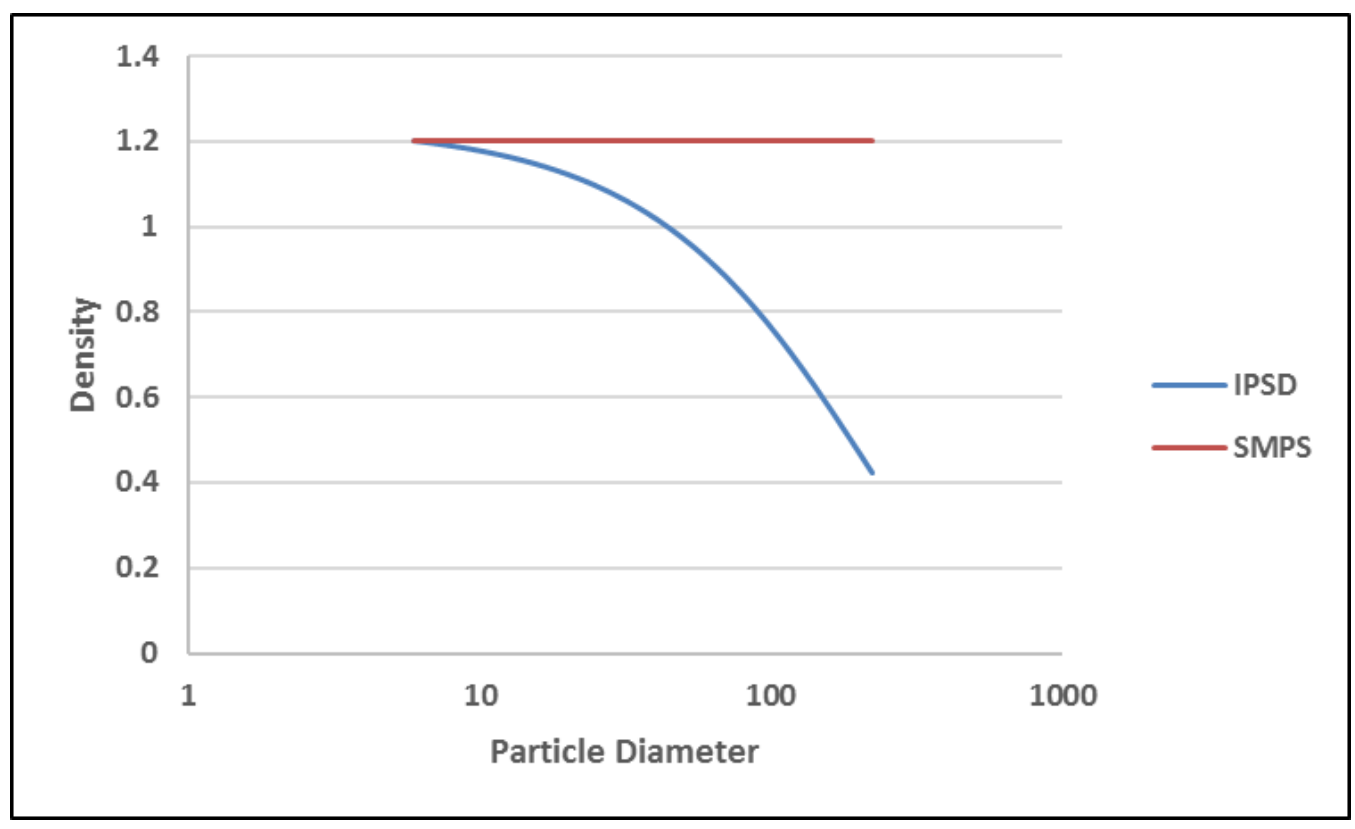

Figure 26: Effective Particle Density Curve 


\subsection{Mass comparison between SMPS and IPSD method.}

This section compares the mass distribution results calculated by the SMPS proprietary software AIM with those calculated by using IPSD method for both modes and at each sample conditioning temperatures. Figure 27 shows the mass distribution results calculated from the data collected at WOT mode by SMPS with sample from CVS and from samples that were treated to different conditioning temperatures $\left(200{ }^{\circ} \mathrm{C}, 150{ }^{\circ} \mathrm{C}, 100{ }^{\circ} \mathrm{C}\right)$.

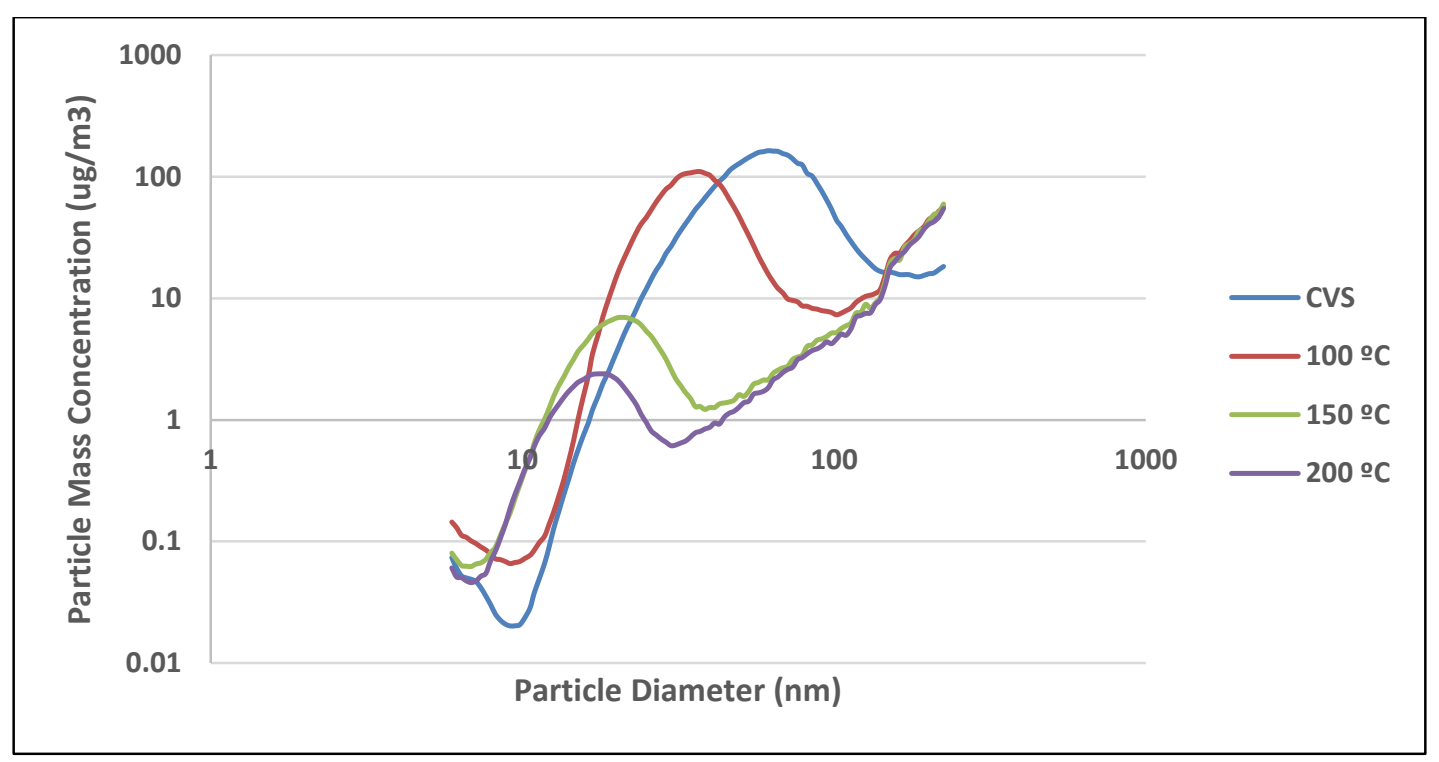

Figure 27: Mass Distributions by SMPS at WOT mode

Figure 28 shows the mass distribution results at WOT mode at different sample conditioning temperatures calculated by using IPSD method. The distribution trend looked similar compared to SMPS mass distributions. The mass concentration of CMD particles of sample with conditioning temperature of $200{ }^{\circ} \mathrm{C}$ given by SMPS was $1.72 \mu \mathrm{g} / \mathrm{m}^{3}$ compared to $1.66 \mu \mathrm{g} / \mathrm{m}^{3}$ given by IPSD method. The mass concentration of CMD particles of sample with conditioning temperature of $150{ }^{\circ} \mathrm{C}$ given by SMPS was $4.64 \mu \mathrm{g} / \mathrm{m}^{3}$ compared to $3.40 \mu \mathrm{g} / \mathrm{m}^{3}$ given by IPSD method. At sample conditioning temperature of $100{ }^{\circ} \mathrm{C}$ the mass concentration of CMD particles given by SMPS was $79.02 \mu \mathrm{g} / \mathrm{m}^{3}$ compared to $70.95 \mu \mathrm{g} / \mathrm{m}^{3}$ given by IPSD method 


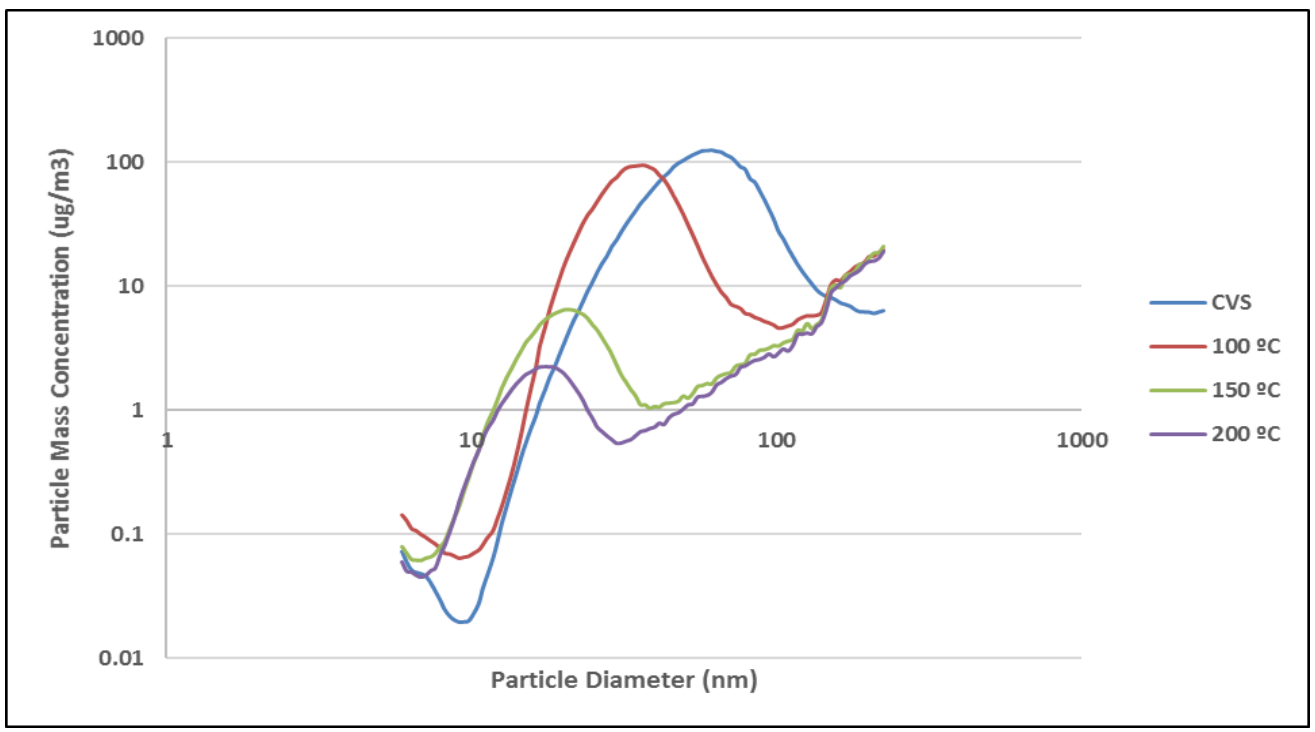

Figure 28: Mass Distributions calculated by IPSD method at WOT mode

Figure 29 shows the mass distribution results calculated from the data collected at idle mode by SMPS with sample from CVS and from samples that were treated to different conditioning temperatures $\left(200{ }^{\circ} \mathrm{C}, 150{ }^{\circ} \mathrm{C}, 100{ }^{\circ} \mathrm{C}\right)$ and figure 28 shows the results calculated by using IPSD method.

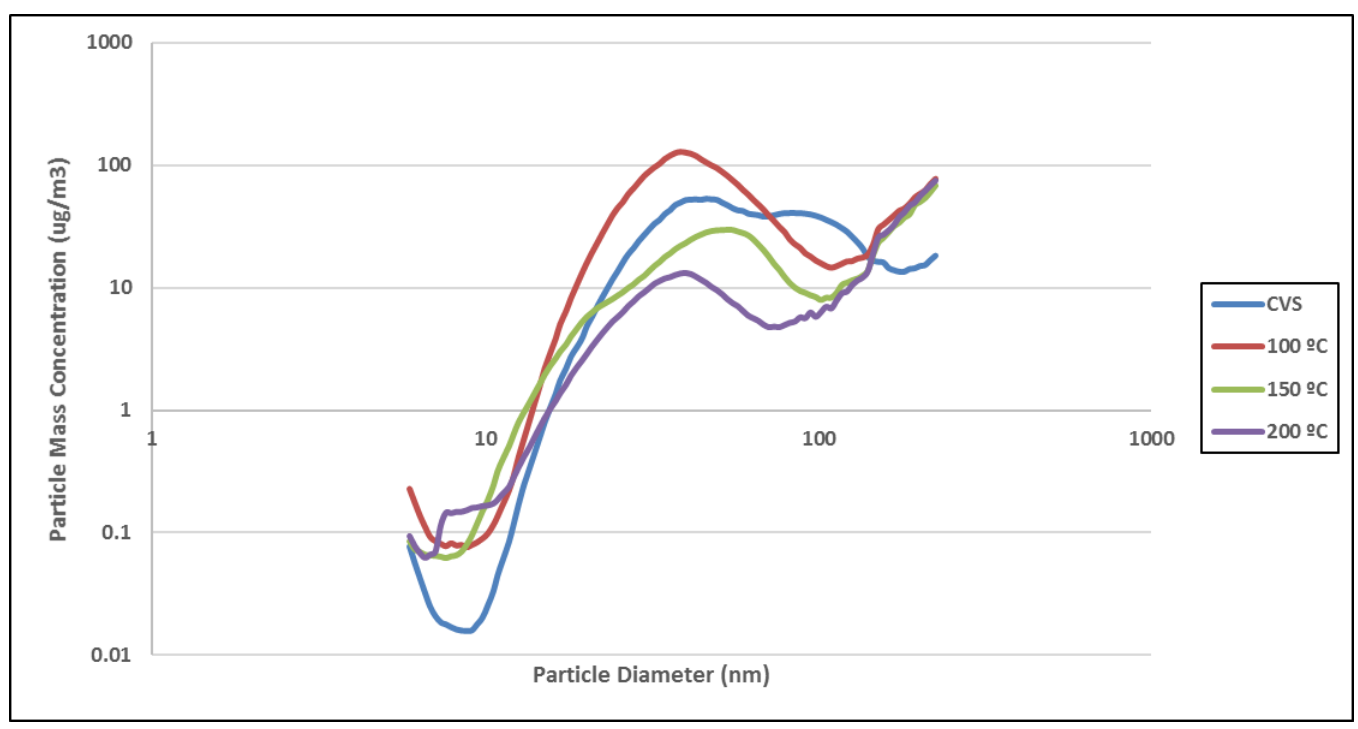

Figure 29: Mass Distributions by SMPS at idle mode

Figure 30 shows the mass distribution results at idle mode at different sample conditioning temperatures calculated by IPSD methods. The distribution trend calculated by 
IPSD method looked similar compared to SMPS mass distributions. The mass concentration of CMD particles of sample with conditioning temperature of $200{ }^{\circ} \mathrm{C}$ given by SMPS was $4.75 \mu \mathrm{g} / \mathrm{m}^{3}$ compared to $4.38 \mu \mathrm{g} / \mathrm{m}^{3}$ given by IPSD method. The mass concentration of CMD particles of sample with conditioning temperature of $150{ }^{\circ} \mathrm{C}$ given by SMPS was $5.23 \mu \mathrm{g} / \mathrm{m}^{3}$ compared to $4.92 \mu \mathrm{g} / \mathrm{m}^{3}$ given by IPSD method. At sample conditioning temperature of $100{ }^{\circ} \mathrm{C}$ the mass concentration of CMD particles given by SMPS was $81.59 \mu \mathrm{g} / \mathrm{m}^{3}$ compared to $72.87 \mu \mathrm{g} / \mathrm{m}^{3}$ given by IPSD method. The concentration values compared to each other were very close.

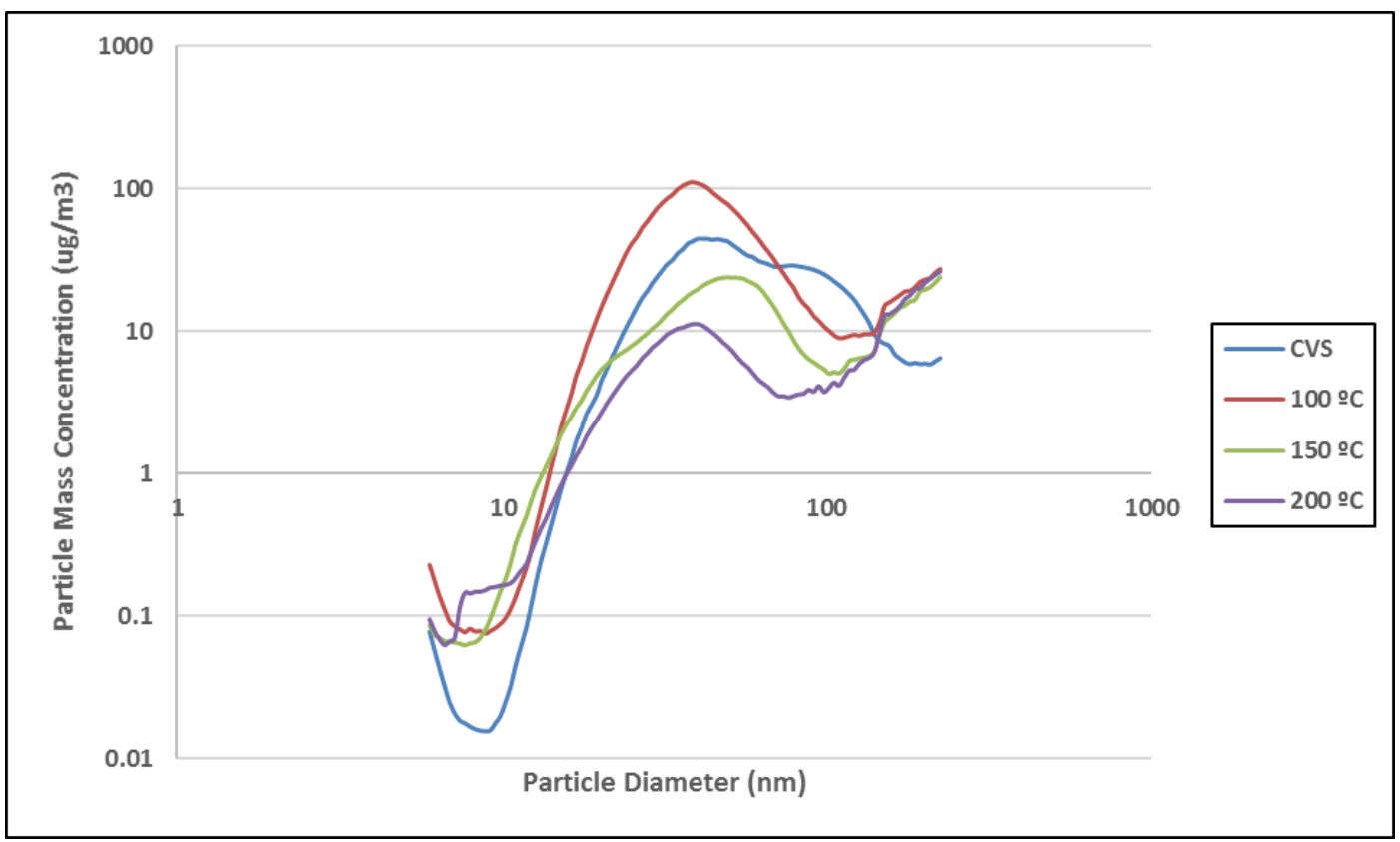

Figure 30: Mass Distributions calculated by IPSD method at idle mode

The mass distributions calculated by IPSD method and SMPS appeared to be very close Table 8 and Table 9 shows the mass concentration values of CMD particles given SMPS and IPSD method. These results shows that mass values given by SMPS and IPSD methods at CMD particles are almost very close which implies a good correlation between them. It is also observed that as the sample conditioning temperature increased during the heat treatment 
process, the mass of the particles significantly reduced as the volatile components were removed during this process. There is a clear trend observed in the mass distributions similar to those observed in the particle size distribution results

Table 8: Mass Concentration of CMD particles from SMPS and IPSD distributions at WOT mode

\begin{tabular}{|c|c|c|}
\hline $\begin{array}{c}\text { Particle Mass Distribution } \\
\text { With Sample Conditioning } \\
\text { Temperature }\end{array}$ & $\begin{array}{c}\text { Mass Concentration of CMD } \\
\text { particles given by SMPS } \\
\left(\boldsymbol{\mu g} / \mathbf{m}^{\mathbf{3}}\right)\end{array}$ & $\begin{array}{c}\text { Mass concentration of CMD } \\
\text { particles calculated by IPSD } \\
\text { method }\left(\boldsymbol{\mu g} / \mathbf{m}^{\mathbf{3}}\right)\end{array}$ \\
\hline $\mathrm{CVS}$ & 35.96 & 31.79 \\
\hline $100^{\circ} \mathrm{C}$ & 79.02 & 70.95 \\
\hline $150^{\circ} \mathrm{C}$ & 4.64 & 3.40 \\
\hline $200{ }^{\circ} \mathrm{C}$ & 1.72 & 1.66 \\
\hline
\end{tabular}

Table 9: Mass concentration of CMD particles from SMPS and IPSD distributions at idle mode

\begin{tabular}{|c|c|c|}
\hline $\begin{array}{c}\text { Particle Mass Distribution } \\
\text { With Sample Conditioning } \\
\text { Temperature }\end{array}$ & $\begin{array}{c}\text { Mass concentration of CMD } \\
\text { particles given by SMPS } \\
\left(\boldsymbol{\mu g} / \mathbf{m}^{\mathbf{3}}\right)\end{array}$ & $\begin{array}{c}\text { Mass concentration of CMD } \\
\text { particles calculated by IPSD } \\
\operatorname{method}\left(\boldsymbol{\mu g} / \mathbf{m}^{\mathbf{3}}\right)\end{array}$ \\
\hline $\mathrm{CVS}$ & 30.21 & 26.84 \\
\hline $100^{\circ} \mathrm{C}$ & 81.59 & 72.87 \\
\hline $150^{\circ} \mathrm{C}$ & 5.23 & 4.92 \\
\hline $200^{\circ} \mathrm{C}$ & 4.75 & 4.38 \\
\hline
\end{tabular}




\section{Conclusions}

A $25 \mathrm{cc}$ handheld trimmer engine was as the source for this study and a Dekati diluter was used for second stage dilution. The Scanning Mobility Particle Sizer was used to measure the particle size distributions and concentrations. The following conclusions are drawn from the results observed in the previous chapter

1) The influence of sample conditioning i.e., heat treatment and dilution certainly is a factor in the measurement of PM size distributions and concentrations.

2) At WOT mode the particle size distributions of the sample in CVS had a CMD of 32.2nm and due to conditioning of the sample it was reduced to $28.9 \mathrm{~nm}, 16.3 \mathrm{~nm}$ and $14.1 \mathrm{~nm}$ at a conditioning temperature of $100{ }^{\circ} \mathrm{C}, 150{ }^{\circ} \mathrm{C}$ and $200^{\circ} \mathrm{C}$ respectively

3) At idle mode the particle size distributions of the sample in CVS had a CMD of $31.1 \mathrm{~nm}$ and due to conditioning of the sample it was reduced to $30 \mathrm{~nm}, 19.5 \mathrm{~nm}$ and $23.3 \mathrm{~nm}$ at a conditioning temperature of $100{ }^{\circ} \mathrm{C}, 150{ }^{\circ} \mathrm{C}$ and $200{ }^{\circ} \mathrm{C}$ respectively

4) Results obtained from the data for the sample in CVS and compared to the data for the heat treated samples, show that the influence of volatile fraction on PM size distribution is reduced with increase in sample conditioning temperatures. So this method of conditioning the sampling i.e., heat treatment process and secondary dilution could be used as an alternative to thermal denuders to eliminate the effect of volatile fraction on the measurements made.

5) The mass distributions given by SMPS and compared to those calculated by using IPSD method are in good correlation with each other. Prior studies also indicated this. 
6) SMPS mass distributions also showed that with conditioning the sample prior to measurements, there was reduction in mass concentrations when compared to the sample in CVS. This shows the influence of volatile particles on mass distributions and the heat treatment process was successful in eliminating the effect of volatile fraction on the measurement made. 


\section{References}

Baron, P. A., \& Willeke, K. (2001). Aerosol Measurement-Principles, Techniques and Applications. New York: John Wiley and Sons.

Braun, C., Ackermann , U., Schwartz, J., Gnehm , H., Rutishauser, M., \& Wanner, H. (1992). Air Pollution and Respiratory Symptoms in Preschool Children (Vol. 145). American Review of Respiratory Disease.

Code of Federal Regulation - CFR. (n.d.). USEPA, 40 Code of Federal Regulations Part 1065.

Czerwinski, J., Kurzwart, M., Mayer, A., \& Comte, P. (2014). Particle Emissions of Modern Handheld Machines. SAE 2014-32-0036.

Czerwinski, J., Wyser-Heusi, M., \& Mayer, A. (2001). Emissions of small 2S-SI-Engine for handheld machinery-Nanoparticulates \& Particulate Matter. SAE Technical Paper 200101-1830.

Dekati. (2016). Dekati Diluter. Retrieved from Dekati Products: http://www.dekati.com/products/Aerosol\%20Sample\%20Conditioning/Dekati\%C2\%AE $\% 20$ Diluter

Dockery, D., Pope, C., Xu, X., Spengler, J., Ware , J., Fay, M., . . Speizer, F. (1993). An Association between Air Pollution and Mortality in Six U.S. Cities. New England Journal of Medicine, 329, , 1753-1759.

Engineering . (2013, March 21). To study two stroke and four stroke petrol engines $\mid$ BME Lab Manual. Retrieved from Engineering: http://engineering.myindialist.com/2013/to-studytwo-stroke-and-four-stroke-petrol-engines-bme-lab-manual/\#.Vx7VSvkrJD9

EPA. (2005). Average Annual Emission Tables: 1970-2002. All Criteria Pollutants. Retrieved from https://www3.epa.gov/ttn/chief/trends/index.html

Favre, C., May, J., \& Bosteels, D. (2013). A Demonstration of Emissions Behaviour of various handheld engine including investigations on particulate matter. SAE 2013-32-9130.

Fritz, O. (2012). GDI Engine Development According EU 6. Graz: AVL Seminar. 
Gerald Liu, Z., Vasys, V. N., \& Dettmann, M. E. (2009). Comparision of Strategies for the Measurement of Mass Emissions from Engines Emitting Ultra-Low Levels of Particulate Matter.

Greenwood, S., Coxon, J., Biddulph, T., \& Bennett, J. (1996). An Investigation to Determine the Exhaust Particulate Size Distributions for Diesel, Petrol, and Compressed Natural Gas Fuelled Vehicles. SAE Technical Paper 961085.

Hamra, G. B., Guha, N., Cohen, A., Laden, F., \& Raaschou-Nielsen, O. (2014). Outdoor Particulate Matter Exposure and Lung Cancer: A Systematic Review and Meta-Analysis. Environmental Health Perspectives.

Health Effects Institute. (1995). A Critical Analysis of Emissions, Exposure, and Health Effects: A Special Report on the Institute's Diesel Working Group. Health Effects Institute, 1995.

Heywood, J. B. (1988). Internal Combustion Engine Fundamentals. McGraw Hill: New York.

Hinds, W. C. (1999). Aerosol Technology-Properties, Behavior and Measurement of Airborne Particles. New York: John Wiley and Sons.

International Agency Research on Cancer. (1989). Diesel and Gasoline Engine Exhausts and Some Nitroarenes. IARC Monograph Vol. 46, 1989.

Khalek, I. S., \& Kittelson, D. B. (1995). Real Time Measurement of Volatile Solid Exhaust Particles Using A Catalytic Stripper. SAE 950236.

Kittelson, D. (2015). Ultrafine Particles Metrics and Indicators. Ultrafine Particles Workshop, U.S. EPA. Research triangle park.

Kittelson, D. B. (1998). Engines and Nanoparticles: A Review. Aerosol Science, 29 No. 5/6, 575588.

Kittelson, D., \& Khalek, I. (1999). Formation of Nanoparticles during Exhaust Dilution.

Kittelson, D., Watts, W. J., \& Arnold, M. (1998). Review of Diesel Particulate Sampling Methods: Supplemental Report No. 2 Aerosol Dynamics, Laboratory ad On-Road Studies. University of Minnesota. 
Knutson, E., \& Lioy, P. (1995). Measurement and Presentation of Aerosol Size Distributions. In B. S. Cohen, \& S. V. Hering (Eds.), Air Sampling Instruments for Evaluation of Armospheric Contaminants (Vol. 8th Edition, pp. 121-136). Cincinnati, Ohio: ACGIH.

Lippmann, M., Gurman, J., \& Schlesinger, R. (1983). Role of Particle Deposition in Occupational Lung Disease. In V. A. Marple, \& L. Y. Benjamin (Eds.), Aerosols in the mining and Industrial Work Environment Volume 1: Fundamentals and Status (Vol. 1, pp. 119-138). Ann Arbor, Michigan: Ann Arbor Science Publishers.

Manufacturers of Emission Controls Association. (2009). Emission Control of Small SparkIgnited Off-Road Engines and Equipment. MECA.

Marple, V. A., Rubow, K. L., \& Behm, S. M. (1991). A Microorifice Uniform Deposit Impactor (MOUDI): Description, Calibration, and Use (Vol. 17). J. Aerosol Science.

Merkisz, J., \& Pielecha, J. (2015). The Process of Formation of Particulate Matter in Combustion Engines. In J. Merkisz, \& J. Pielecha, Nanoparticle Emissions from Combustion Engines. Switzerland: Springer International.

Monn, C., Braendli, O., Schaeppi, G., Schindler, C., Ackermann-Liebrich, U., \& Leuenberger, P. (1995). Particulate matter $<10 \mu \mathrm{m}$ (PM10) and total suspended particulates (TSP) in urban, rural and alpine air in Switzerland. In Atmospheric Environment (Vol. 29, pp. 2565-2573). Elsevier.

National Air Pollution Control Administration. (1969). Air Quality Criteria for Particulate Matter. U.S. National Air Pollution Control Administration.

National Institute for Occupational Safety and Health. (1988). Carcinogenic Effects of Exposure to Diesel Exhaust. Carcinogenic Effects of Exposure to Diesel Exhaust. CIB.

Rohr, A. C., \& Wyzga, R. E. (2012). Attributing health effects to individual particulate matter constituents. Electrical Power Research Institute. Palo Alto, CA, USA.

Smith, S., Cheng, Y.-S., \& Yeh, H. (2001). Deposition of Ultrafine Particles in Human Tracheobronchial Airways of Adults and Children. Aerosol Science and Technology, 3, 697-709. 
Stern, A., Wohlers, H., Boubel, R., \& Lowry, W. (1973). Fundamentals of Air Pollution (Vol. 3rd Edition). Orlando, Florida: Academic Press.

Strak, M., Janssen, N. A., Godri, K. J., Gosens, I., Mudway, I. S., Cassee, F. R., . . Hoek, G. (2012). Respiratory Health Effects of Airborne Particulate Matter: The Role of Partcile Size, Composition and Oxidative Potential - The Raptes project. Environ Health Perspect.

Suresh, A., \& Johnson, j. H. (2001). A study of Dilution Effects on Particle Size Measurement From a Heavy Duty Diesel Engine with EGR. SAE Technical Paper No. 2001-01-0220.

TSI. (1999). Model 3936 SMPS Instruction Manual.

TSI. (2002). Model 3022A Condensation Particle Counter. TSI.

US EPA. (n.d.). Retrieved from Particulate Matter | Air and Radiation |USEPA: https://www3.epa.gov/pm/

Venkatasubramaniam, K. C. (2007). Effect of Dilution Method on Diesel Exhaust Particulate Matter, Concentrations and Size Distributions. Morgantown: Department of Mechanical and Aerospace Engineering, WVU.

Volckens, J., Braddock, J., Snow, R. F., \& Crews, W. (2007). Emissions profile from new and in-use handheld, 2-stroke engines. In Atmospheric Environment (Vol. 41, pp. 640-649). 